\title{
MOUNT SAN JACINTO STATE PARK VISITOR ATTRIBUTES, PREFERENCES, AND PERCEPTIONS
}

\author{
A Thesis \\ Presented to \\ the Faculty of California Polytechnic State University, \\ San Luis Obispo \\ In Partial Fulfillment \\ of the Requirements for the Degree \\ Master of Science in Agriculture, with Specialization in \\ Recreation, Parks, \& Tourism Management
}

by

Katherine Elizabeth Wassenberg

June 2009 
(C) 2009

Katherine Elizabeth Wassenberg

ALL RIGHTS RESERVED 


\section{COMMITTEE MEMBERSHIP}

TITLE: Mount San Jacinto State Park Visitor Attributes, Preferences, and Perceptions

AUTHOR: Katherine Elizabeth Wassenberg

DATE SUBMITTED: June 2009

COMMITTEE CHAIR: William Hendricks, Professor

COMMITTEE MEMBER: Jerusha Greenwood, Assistant Professor

COMMITTEE MEMBER: David Gillette, Professor 


\begin{abstract}
Mount San Jacinto State Park Visitor Attributes, Preferences, and Perceptions Katherine Elizabeth Wassenberg
\end{abstract}

The purpose of the study was to assess Mount San Jacinto State Park visitor attributes, visit attributes, preferences, and perceptions. Visitor surveys were conducted at two predetermined points within Mount San Jacinto State Park Wilderness Area, the entrance to Long Valley and adjacent to the Long Valley Ranger Station, during summer 2008. Three hundred and seventy-eight subjects completed one of the two visitor surveys (97.68\% response rate), $256(67.7 \%)$ completed the Long Valley Survey and $122(32.3 \%)$ completed the Wilderness Survey. The subjects were mostly male, married, from California, and White or Latino/Hispanic. The average age was 45 years old with some college education and relatively high levels of income (42.4\% reported annual household incomes above $\$ 100,000)$. The mean number of previous park visits was 15 and the subjects visited the park an average of 3.74 times in 2008. The amount of time spent in the wilderness was an average of 4.68 hours. Most visitors participated in photography, wildlife viewing, shopping at the gift shop, bird watching, visiting the visitor center, eating at the snack bar, and hiking. The subjects agreed that conditions in the park are safe and that there are adequate ranger patrols. Wilderness visitors had significantly higher agreement scores for adequate ranger patrols, too many people at Mountain Station, and that they prefer to see fewer people in the park. The overall crowding mean score was slightly below "somewhat crowded" with Wilderness visitors reporting significantly higher levels of crowding than Long Valley visitors. Visitor perceptions of 
problems in the park were rated "not a problem" for all items; however, Wilderness visitors perceived encounters of large groups on a trail and restrooms needing cleaning to be more of a problem than was perceived by Long Valley visitors. Worn trails, side trails, and erosion along trails were the conditions most noticed by the subjects.

Significantly more Wilderness visitors than Long Valley visitors noticed erosion along trails and tree root exposure on trails. 
The author would like to thank Dr. William Hendricks, Dr. Jerusha Greenwood, and Dr. David Gillette for their guidance and encouragement. The California State University Agricultural Research Initiative and California State Parks for financial assistance. Jeff Reimer, Instructional Support Technician, for invaluable technical assistance and support.

TABLE OF CONTENTS 


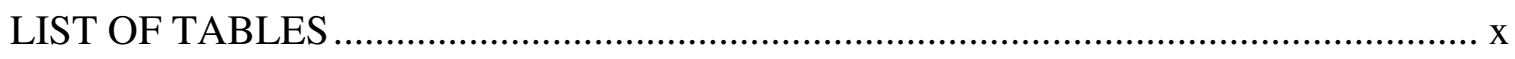

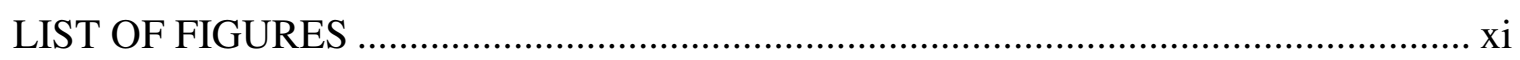

\section{CHAPTER}

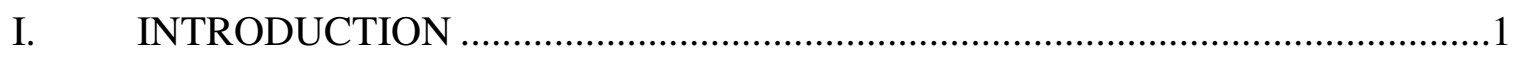

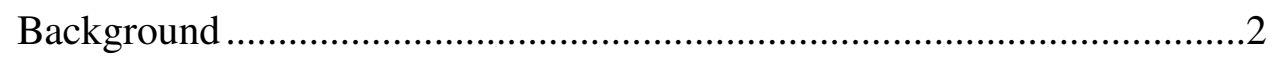

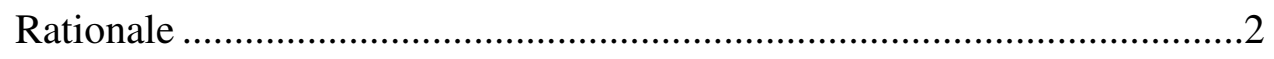

Purpose of Study ...........................................................................

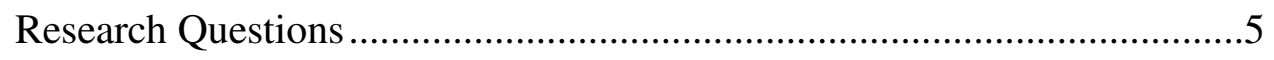

Delimitations ................................................................................. 6

Definition of Key Terms ...................................................................6

Visit attributes ...............................................................6

Visitor attributes.............................................................

Visitor attitudes and preferences............................................6

Visitor perceptions .........................................................

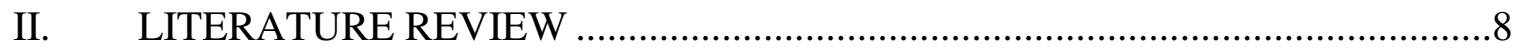

Visit and Visitor Attributes ..........................................................

Early attributes research...................................................

Later attributes research ................................................. 12

Integration of attributes research ........................................16

Visitor Attitudes and Preferences .................................................... 17

Early attitudes and preferences research ................................17

Later attitudes and preferences research ...................................19 
Visitor Perceptions

Research on perceptions of social impacts ..............................24

Research on perceptions of environmental impacts....................26

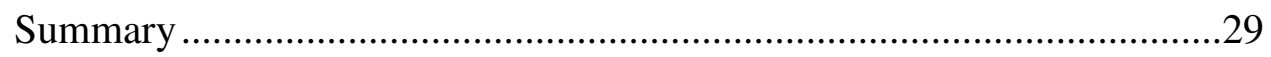

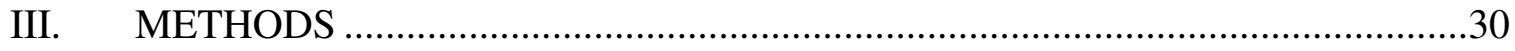

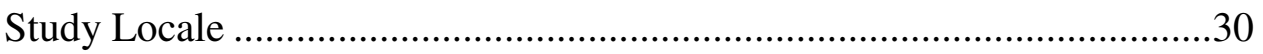

Description of Subjects ............................................................. 31

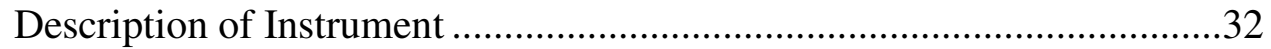

Long Valley Visitor Survey ..................................................33

Wilderness Visitor Survey .................................................34

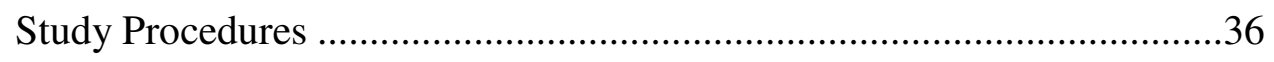

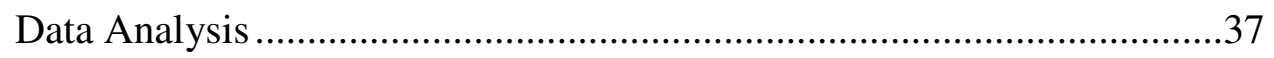

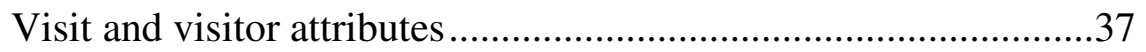

Visitor attitudes and preferences............................................38

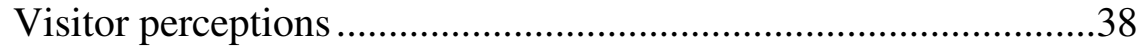

Relationships between visit and visitor attributes, visitor attitudes and preferences, and visitor perceptions .......................39

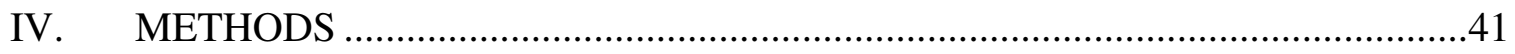

Visitor Attributes ........................................................................4 41

Visit Attributes............................................................................44

Visitor Attitudes and Preferences ..........................................................53

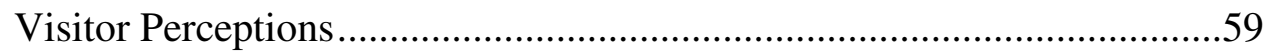




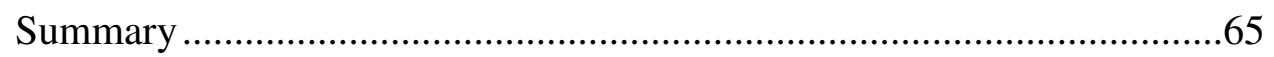

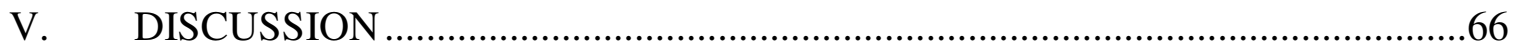

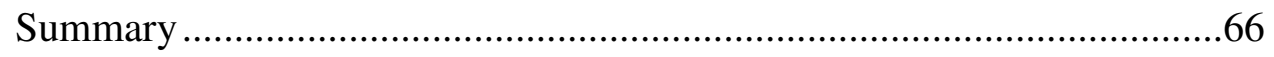

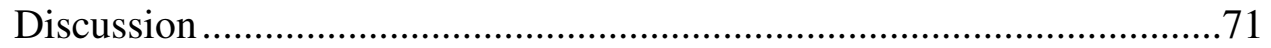

Managerial Implications .......................................................... 72

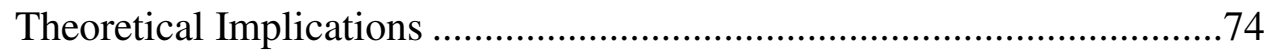

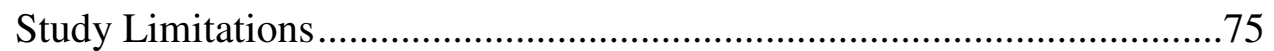

Future Research ........................................................................... 77

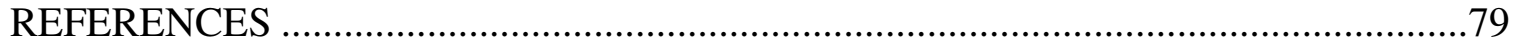

\section{APPENDICES}
A. Long Valley Visitor Survey.
.94

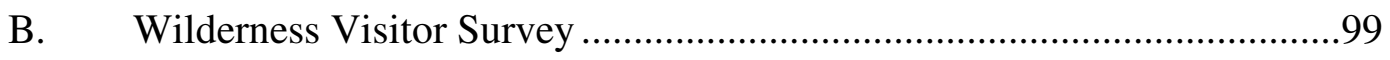
C. Informed Consent Form

\section{LIST OF TABLES}




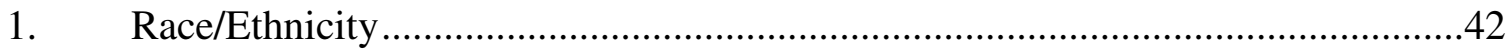

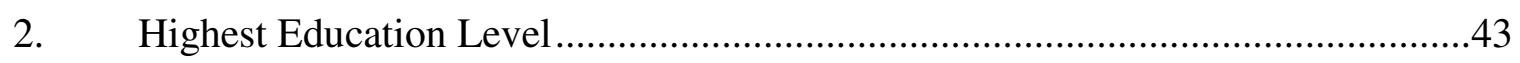

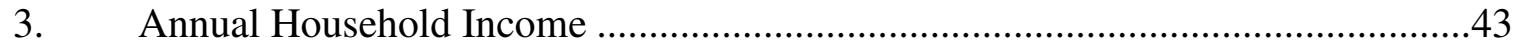

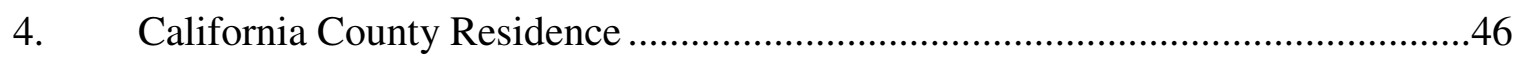

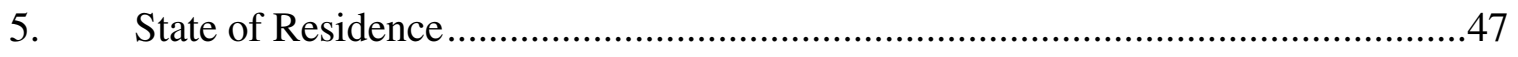

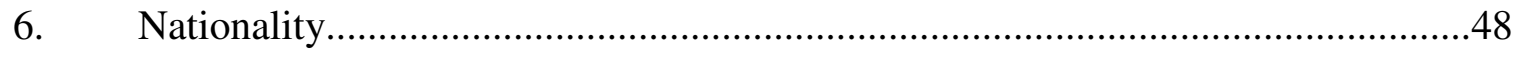

7. How Subjects Obtained Information about the Park ........................................49

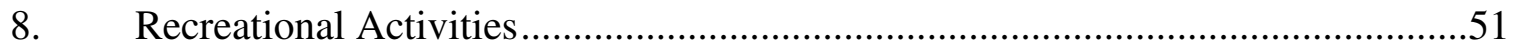

9. Activity Participation by User Type ….....................................................52

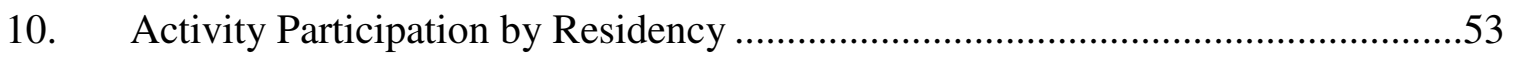

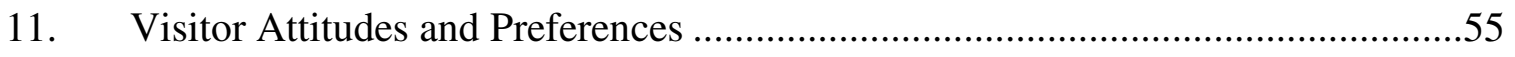

12. Visitor Attitudes and Preferences by Gender..............................................56

13. Visitor Attitudes and Preferences by Residency .........................................57

14. Visitor Attitudes and Preferences by Visit/Visitor Attributes .............................58

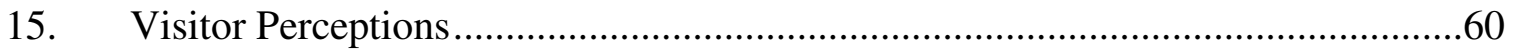

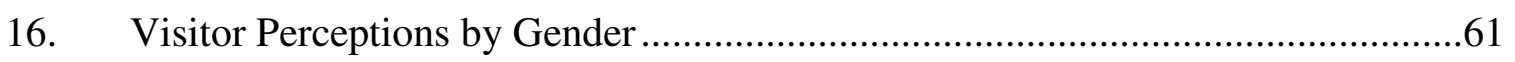

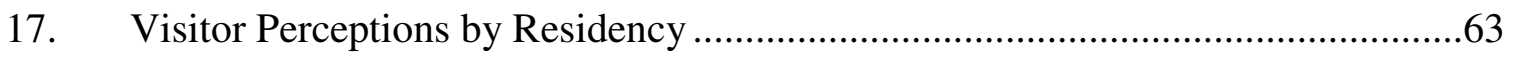

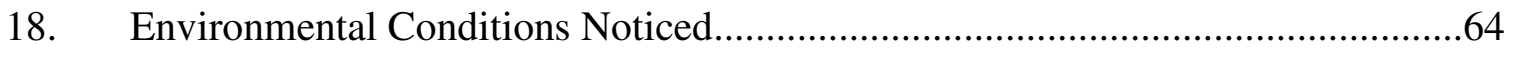

19. Visitor Perceptions by Visit/Visitor Attributes...............................................65

\section{LIST OF FIGURES}


Figure

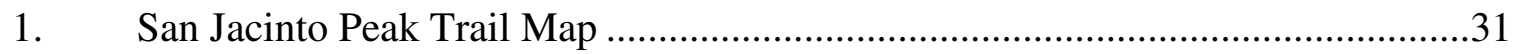

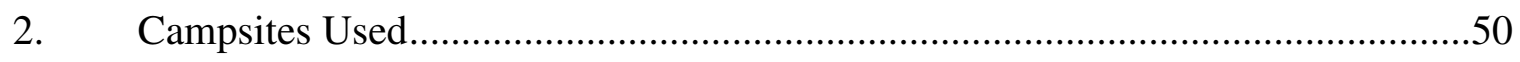

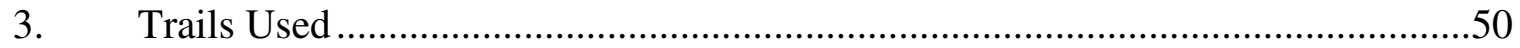




\section{CHAPTER 1}

\section{INTRODUCTION}

Understanding wilderness use has been a vital component of visitor management, as this information assists in policy formation, managerial strategies, resource protection, and planning. Wilderness use has often been characterized as human experiences and activities when visiting a designated wilderness area. Flood and McAvoy (2000) iterated that "[f]or many visitors, wilderness is not just a nice place to visit. It is a place for significant contemplative experiences and has the power to enhance the quality of one's life" (p. 197). Original interest in wilderness use grew out of concern for preserving the integrity and quality of wild areas.

As early as the 1930 s connections were being drawn between visitors to wild areas and maintenance of the areas' atmosphere. Leopold (1934) stated that "the salient geographic character of outdoor recreation, to my mind, is that recreational use is selfdestructive. The more people are concentrated in a given area, the less is the chance of their finding what they seek" (p. 539). Two years later, in the High Sierra, Sumner (1936) recognized that the land maintains a human saturation point that once surpassed will no longer provide the experiences that humans seek. Further, he asserted that in some High Sierra areas, this point has already been surpassed. This emphasis on a saturation point was revisited a decade later, when Wagar (1946) concluded that human

populations, similar to wild birds, have maximum concentrations that can be sustained in one area. Publications like Conservation and Priorities in Wilderness Areas (Allen, 1948), The Dilemma of Our Parks (Drury, 1949), and Wilderness: A Wasted Heritage 
(Sierra Club, 1949) represented the growing demand to have wilderness visitors'

preferences and motivations taken into consideration when determining wilderness management and recreation policies.

\section{Background}

The 10,000-acre Mount San Jacinto State Park consists mainly of a designated wilderness area and ranges in elevation from sea-level to the second highest mountain in southern California, the 10,834-foot San Jacinto Peak. This region is biodiverse, with over 500 native plant species and numerous threatened or endangered animal species (Cantu, Housser, Hoffman, \& Rohling, 2002). The wilderness area is accessible by the Palm Springs Aerial Tramway, which “carries passengers about two-and-a-half miles from the desert to its mountain terminus, at an elevation of more than 8,500 feet" (Krantz, 2007, p. 2) or by the hiking trail system near the town of Idyllwild, CA.

California State Parks has dictated that "[e]veryone entering the wilderness area for the day or for camping must have a permit in their possession. Day use wilderness permits are free and are available at the State Park Headquarters in Idyllwild or at the Long Valley Ranger Station” (2007). During summer months, wilderness areas have often reached their set carrying capacity limits and numerous potential campers are turned away. Group sizes are limited to 15 people and dogs are not permitted in the wilderness area (California State Parks, 2007).

\section{Rationale}

As any level of wilderness use has the potential to impact wilderness users' experiences, as well as natural and cultural resources, Watson, Cole, Turner, and 
Reynolds (2000) argued that "wilderness use information is absolutely essential for examining and testing" (p. 2) the underlying foundations of wilderness management. Such information has become essential because: "(1) the management of wilderness visitors is a priority, and (2) in order to make effective management decisions, the manager must have reliable information about visitor use of wilderness" (p. 1). Wilderness use research has been undertaken using a variety of methods to obtain valuable visitor information. Three categories of wilderness use variables that have been measured include visit and visitor attributes, visitor attitudes and preferences, and visitor perceptions.

Visit and visitor attributes provide information regarding the background, characteristics, and behavior of visitors. Watson, et al. (2000) defined visit attributes as "relevant characteristics of visits" (p. 9). Such information may include the length of stay, group size, travel method(s), temporal and spatial use distribution patterns, or activity participation. Visitor attributes describe the "traits characterizing wilderness visitors" (p. 9). This may include information such as race, gender, education, income, or past wilderness experience and knowledge. Clark and Leung (2007) suggested that understanding such visitor demographics may reveal a connection between recreation experience and visitor attitudes about the environment.

Visitor attitudes and preferences are additional key variables in understanding wilderness visitors. Watson, et al. (2000) described attitudes and preferences as: A means of assessing (1) the qualities and characteristics of the wilderness experience important to the visitor, (2) how these expectations are met in practice, (3) current levels of 'satisfaction,' (4) 'satisfaction in comparison with previous 
visits to the wilderness area or visits to other areas, and (5) perceived 'defects' or causes of dissatisfaction. (p. 17)

Aspects of the wilderness experience that have been of interest to researchers and managers include the number and type of social encounters, number of wild animals seen, extent of campsite vegetation loss, or amount of litter (Watson, Williams, Roggenbuck, \& Daigle, 1992). Assessments of such aspects of visitor attitudes and preferences can provide insight regarding visitor experiences. Lucas (1987) contended that understanding visitor attitudes and preferences is particularly important when visitors are dissatisfied or experience recreation conflict.

Visitor perceptions allow researchers to establish a reasonable picture of the areas and problems that concern visitors (Watson, et al. 2000). This picture of visitor concerns can be reached through an understanding of "visitor perceptions of conditions... [visitor] reactions to perceived conditions... [visitor] opinions on current conditions, and how [visitors perceive conditions] to be changing over time" (p. 15). Dorwart, Leung, and Moore (2004) stressed that visitor experiences are directly effected by visitor perceptions, and that these visitor perceptions, which may focus on a variety of resource impacts, significantly influence the quality of their experiences. Noe, Hammitt, and Bixler (1997) concluded that area managers should be more perceptive and responsive to visitor perceptions and how these perceptions influence the quality of visitor experiences.

Maintaining quality visitor experiences and upholding the ecological integrity of protected areas has required that comprehensive wilderness use and visitor information be both collected and considered during the formation of management policy. Understanding this requirement, the Mount San Jacinto State Park General Plan 
advocated "an assessment of the current trail system within the park based upon capacity objectives and visitor experiences...[to] assist managers in developing visitor management plans, setting policy and implementing management actions and strategies" and to "obtain information regarding" visitor segments, use levels, temporal and spatial distribution, as well as visitor attitudes and preferences and visitor perceptions of social, and environmental impacts (Hendricks \& Greenwood, 2007, p. 1, 3).

Purpose of Study

The purpose of this study was to assess Mount San Jacinto State Park visit and visitor attributes, visitor attitudes and preferences, and visitor perceptions of social and environmental impacts.

\section{Research Questions}

1. What are Mount San Jacinto State Park visit attributes?

2. What are Mount San Jacinto State Park visitors' attributes?

3. What are Mount San Jacinto State Park visitors' attitudes and preferences towards crowding, displacement in the park, park safety, and management policies?

4. What are Mount San Jacinto State Park visitors' perceptions of social and environmental impacts?

5. Does Mount San Jacinto State Park visitor activity participation differ by user type or by residency?

6. Do Mount San Jacinto State Park visitors' attitudes and preferences differ by user type, gender, residency, number of nights spent in the wilderness, number of miles hiked in the wilderness, number of total previous park visits, number 
of previous 2008 park visits, group size, or by number of hours spent in the wilderness?

7. Do Mount San Jacinto State Park visitors' perceptions of social and environmental impacts differ by user type, gender, residency, number of nights spent in the wilderness, number of miles hiked in the wilderness, income levels, group size, or by hours spent in the wilderness?

\section{Delimitations}

This study was conducted within Mount San Jacinto State Park near the Long Valley Ranger Station. A visitor survey detailing visit and visitor attributes, visitor attitudes and preferences, and visitor perceptions was conducted on four randomly selected weekends in July, August, and September 2008. Survey administrators randomly selected park visitors using systematic random sampling, conducted approximately five minute, oral interviews in English, and recorded participant responses with a Compaq PDA.

\section{Definition of Key Terms}

The following terms are defined as used in this study:

Visit attributes. Relevant characteristics of visits, such as length of stay, number of people per group, and activities participated in.

Visitor attributes. Traits characterizing wilderness visitors, such as experience, demographics, and preferences (Watson et al., 2000).

Visitor attitudes and preferences. "A means of assessing (a) the qualities and characteristics of the wilderness experience important to the visitor, (b) how these 
expectations are met in practice, (c) current levels of 'satisfaction,' (d) 'satisfaction in comparison with previous visits to the wilderness area or visits to other areas, and (e) perceived 'defects' or causes of dissatisfaction" (Watson et al., 2000, p. 17)

Visitor perceptions. "Visitor perceptions of conditions, and their reactions to perceived conditions...visitor opinions on current conditions, and how conditions are perceived to be changing over time...provid[ing] a good perspective on the extent to which problems are a concern to visitors" (Watson et al., 2000, p. 23) 


\section{CHAPTER 2}

\section{LITERATURE REVIEW}

Since the conception of the Wilderness Act in 1964, understanding wilderness use and wilderness visitors has become a pivotal objective of much outdoor recreation research. The process for evaluating wilderness use and wilderness visitors has emerged from a far-reaching blend of fields, methods, and perspectives. Glaspell and Puttkamer (2001) offered a succinct description of this evolution:

While much of the early [recreation] research sought to identify simple relationships between setting attributes and visitor experiences, recent research efforts have expanded to address the values people hold for wilderness (including nonrecreation values), a variety of types and dimensions of wilderness experiences, and factors that influence those experiences. (p. i)

The purpose of this review of literature is to examine the evolution of three aspects of wilderness use: visit and visitor attributes, visitor attitudes and preferences, and visitor perceptions.

\section{Visit and Visitor Attributes}

In outdoor recreation research, visit and visitor attributes have typically been measured to obtain information about wilderness, park, and forest visitors. Watson, Cole, Turner, and Reynolds (2000) defined visit attributes as relevant characteristics of visits. Such information may include the length of stay, group size, travel method(s), temporal and spatial use distribution patterns, or activity participation. Visitor attributes are described as the traits characterizing wilderness visitors. This may include information 
such as race, gender, education, income, or past wilderness experience and knowledge. This section discusses early and later research pertaining to visit and visitor attributes, as well as how this research integrates with other wilderness visitor research.

Early attributes research. Early research focused on measuring descriptive visit and visitor attributes. Borrie and Brizell (2001) asserted that early recreation "researchers were primarily interested in the numbers of outdoor participants, the activities in which they participated, and their basic socio-demographics...provid[ing] a baseline for use levels and the beginnings of an empirical foundation" (p. 29-30). Lucas (1987) explained that this research was often hampered by researchers' lack of accessibility to wilderness users, which resulted in small samples, large variances, and expensive studies. Empirical research has been undertaken within specific recreation areas in order to better understand wilderness users and wilderness use (e.g., Lucas, 1964a, 1964b; Moss, Shackleford, \& Stokes, 1969; Murray, 1974; Stone \& Taves, 1956; Taves, Hathaway, \& Bultena, 1960). Results from such early visitor studies indicated that while activity aggregations varied according to study location, most wilderness visitor and visit attributes tended to be similar across locations (Lucas, 1987).

Bultena and Taves (1961) reported on findings obtained from 428 interviews in two studies that researched the characteristics of visitors to Quetico Provincial Park and Superior National Forest. They found that visitors could be categorized into the two main users groups of campers and canoeists, $85 \%$ of respondents live in urban areas and $50 \%$ reside in metropolitan areas with populations of 500,000 or greater.

The Outdoor Recreation Resources Review Commission (ORRRC) was established in 1958 to address the outdoor recreation needs of the nation (Outdoor 
Recreation Resources Review Commission, 1962a) and has been cited as the beginning of serious social science research on outdoor recreation (Manning, 2000). The commission provided a new and comprehensive look at outdoor recreationists, including characteristics and activity interests, in 27 volumes and numerous studies (as cited in Merriam, 1970; Zinser, 1995). ORRRC conducted a nationwide outdoor recreation survey of 16,000 people. Results from this study provided an extensive view of visit and visitor attributes to a range of nature/natural areas. Specific to wilderness areas, ORRRC surveyed users in seven wildernesses, but only collected sample sizes large enough to analyze in three of the wilderness areas. These were descriptive, census-like reports focusing on visit and visitor attributes, such as user characteristics and user types (Outdoor Recreation Resources Review Commission, 1962b). Through these studies, the ORRRC determined that wilderness areas should have "no development of public roads, permanent habitations, or recreation facilities of any sort. Their avoidance is the keystone of management" (Outdoor Recreation Resources Review Commission, 1962a, p. 113).

Hendee, Catton, Marlow, and Brockman (1968) studied 1,950 Washington and Oregon wilderness users to determine visit and visitor attributes. Results indicated that Pacific Northwest wilderness visitors are generally more educated than the nation as a whole, travel in small groups, and make approximately five 2-3 day trips each year. Additionally, this study led to the development of the Wilderness Purism Scale, as well as to dispel misconceptions about wilderness use and users and elucidate the true nature of the wilderness recreation experience (Lucas, 1987). 
Merriam and Ammons (1968) conducted a descriptive study of summer users in three preserved areas in Montana's northern Rocky Mountains: the Bob Marshall Wilderness, the Mission Mountain Primitive Area, and Glacier National Park. Through 108 questionnaires and interviews, researchers found that visitors to these areas differed greatly in terms of residence, socioeconomic status, activity aggregations, and methods of travel. Although mean ages varied by study location, respondents were between 13-84 years old, generally traveled in groups of $4-5$, and over $50 \%$ had previous experience at the study area. Additionally, researchers discovered that the majority of respondents in the Bob Marshall Wilderness and the Mission Mountain Primitive area were Montana residents, while $81 \%$ of Glacier National Park respondents were from other states. The results led researchers to conclude that the differing user characteristics of the three areas require different management policies.

Such conclusions led researchers to study visit and visitor attributes, not just to describe what was going on in wilderness areas, but also to recommend how wilderness area managers could most effectively implement potential carrying capacities (e.g., Burch \& Wenger, 1967; Dana, 1957; Frissell \& Stankey, 1972; Lime \& Stankey, 1971; Lucas, 1964b; Merriam, 1963; Merriam, 1970; ORRRC, 1962b; Stankey, 1973; Wagar, 1964). Lucas (1987) indicated that social carrying capacity research largely focused on solitude as a characteristic of the wilderness experience; additionally, wilderness researchers quickly recognized social carrying capacity as an important aspect of management policy.

As early research progressed, researchers found that wilderness visits and visitor attributes could be used in various ways besides the original purposes of exploring who was using wilderness areas and establishing carrying capacity limits. For example, Burch 
(1966) studied visitors to the Three Sisters Wilderness Area in Oregon for relationships between age, family structure, and recreational areas visited. He found that both visitors and visits can be clustered into segments, which could assist managers in designating specific use areas and in determining levels of development.

Later attributes research. In the 1970s wilderness use research focused on relating visit and visitor attributes to management issues, like group-size restrictions, use policies, permit policies, or user conflict mitigation (e.g., Bratton, Hickler, \& Graver, 1977; Jubenville, 1971; Kennedy \& Brown, 1976; Lime, 1972; Murray, 1974; Nielsen \& Shelby, 1977; Stankey, Lucas, \& Lime, 1976).

Lime (1972) posed four research questions to wilderness area managers who were considering group-size limit reductions. These questions addressed the amount of wilderness use by large groups, the potential user displacement consequences, who would be most effected, and how other visitors are effected by large groups. To answer these questions, Lime analyzed data from a Superior National Forest's Boundary Waters Canoe Area visitor study and information collected from the mandatory travel permits to determine who visited Boundary Waters Canoe Area. The results indicated that $8 \%$ of parties visiting the Boundary Waters Canoe Area are large groups (9+ people); that large groups generally stay longer, travel by canoe, and have a greater spatial distribution than smaller groups; and that most large parties are organized youth groups. Additionally, the research showed that most large groups are nonlocal user groups that would be difficult to inform of the group-size reduction limits, but would also be greatly impacted by the reduction. These descriptive visit and visitor attribute data were used to recommend a timetable to reduce the group-size limit over an extended period of time. 
Lime and Buchman (1974) analyzed data obtained from a visitor use report in the Boundary Waters Canoe Area, including data on mode of transportation, visitor days, entry point, travel zone, group size, and recreational activities. They combined their data analyses with a review of literature, focusing on obtaining general patterns of wilderness use from wilderness area permit systems to illustrate how visitors were traveling within the area. The researchers concluded that area managers could maintain the quality of visitor experiences and sustain an area's physical resources through reliable visit attributes, specifically use distribution patterns.

Echelberger and Moeller (1977) stated that eastern United States backcountry areas should be managed with consideration to area users and users' anticipations of the backcountry experience. The researchers surveyed Cranberry backcountry visitors to provide descriptive information on eastern National Forest visitors, as well as visitor opinions about area management. Results indicated that approximately $75 \%$ of visitors are male, have previous experience in this particular backcountry, and are not affiliated with outdoor organizations. Additionally, $60 \%$ of visitors are under 30 years old and are trout fishermen. Cranberry backcountry visitors are more educated and slightly more affluent than the entire US population. Visit attributes indicated that visitors generally come in groups of 2-5 people, stay from 1-3 days, and visit several times a year. Analyses of these results revealed seven users groups: voluntary registrants, involuntary registrants, spring visitors, summer visitors, fall visitors, fishing-gate entrants, and nonfishing-gate entrants. The researchers concluded that future management policies decisions in the Cranberry backcountry should employ these results but that more research needs to be done for other eastern wilderness areas. 
Lucas (1985) conducted multiple surveys to measure use trends in the Bob Marshall Wilderness over 12 years. This research documented a reduction in the growth of wilderness use, that visitors' mode of transportation was changing from horses to hiking, and an increase of user conflicts and visitor complaints about trail conditions. Such evidence could be used to assist area managers in updating management strategies and potential use policies.

Roggenbuck and Lucas (1987) conducted an in-depth analysis and synthesis of previous wilderness visitor descriptive studies. Their work draws numerous relationships between visit and visitor attributes by comparing data collected from previous empirical studies. They found that group size is related to activity aggregations, length of stay is related to user types, use distribution patterns are related to user types, activity aggregations are related to user types, and that different wilderness areas attract people with different occupations and different income levels. The researchers indicated that these relationships suggest that understanding the visit and visitor attributes in a specific wilderness area will allow area managers to better meet visitor needs.

Watson, Cordell, and Hartmann (1989) surveyed US Forest Service wilderness users, at 18 different wildernesses, and nonwilderness users, at 55 nonwilderness areas, to examine whether wilderness users can be demographically differentiated from general outdoor users. Although data analyses indicated strong similarities between the two user groups, their research indicated another important finding. Specifically, descriptive statistics revealed that user activity participation and length of stay affect spatial and temporal travel distribution patterns. This information may allow managers to implement effective use and permit policies. 
Manfredo, Fishbein, Haas, and Watson (1990) employed telephone surveys to determine and compare the attitudes of Wyoming and Montana residents with nationwide attitudes about prescribed fire policies after the severe 1988 Yellowstone National Park wildfires. Researchers found that respondents' level of fire and fire policy knowledge is positively correlated to respondents' support of prescribed fire policies. These findings suggested that as levels of knowledge affect support of certain regulations, managers may be able to correct low visitor observance of regulations by implementing visitor education.

Watson, Niccolucci, and Williams (1993) conducted studies in the John Muir Wilderness, Sequoia-Kings Canyon National Parks, and Charles C. Deam Wilderness to consider the conflicts resulting between and the impacts of hikers and horse users. Results from these studies indicated differences between group size and user type, specifically showing that groups traveling with recreational pack animals are often larger than groups hiking without pack animals. Managers can employ information derived from these findings to increase their understanding about the behaviors of various user types, set use policies, and possibly reduce user conflicts.

Chavez (2001) summarized and analyzed data from 30 visitor contact studies conducted throughout California from 1989 to 1998. The purpose of this compilation was to identify visitor characteristics to assist managers whose sites, especially wilderness areas, see increasing visitation from minority groups. The findings indicated that different sites draw different ethnic groups; males are more likely to visit wilderness areas and engage in off-road vehicle riding and mountain biking; most respondents claim an annual household income between $\$ 20,000-\$ 60,000$ and work as manual laborers or 
semi-professionals; and that visitors mainly speak English or Spanish and were born in the United States or Mexico. Chavez cited management misconceptions of minority groups and minority group misunderstandings of management policies as a need for understanding the visitor characteristic data collected in these studies. Specifically, she argued that understanding the impacts of visitors' socio-demographic variables on resource management can provide solutions for "the challenge [of] managing shifting visitor populations" (p. 2).

Integration of attributes research. Visit and visitor attributes have provided critical information about wilderness use that should be used in the formation and evaluation of area management. In fact, Roggenbuck and Lucas (1987) argued that “[w]hen such visitor information is lacking, decisions must be based largely on intuition. Better knowledge of visitor characteristics increases the professionalism of wilderness management and can improve the quality of visitor experiences" (p. 205). Although visit and visitor attributes are clearly beneficial as a subject of interest, Clark and Leung (2007) suggested that understanding such visitor demographics may reveal a connection between recreation experience and visitor attitudes towards the environment. Freimund and Cole (2001) explained that recreation research has transitioned from descriptive statistics to assessments of the relationships between visit and visitor attributes, location attributes, and the quality of visitor experiences. At the same time that interest in visit and visitor research was increasing, some scientists were finding connections to visitor satisfaction. 


\section{Visitor Attitudes and Preferences}

Watson, et al. (2000) described five aspects of visitor attitudes and preferences, including expectations of wilderness experience characteristics, how those expectations are met, level of satisfaction, comparison of satisfaction from previous wilderness experiences, and perceived causes of dissatisfaction. Wilderness experience characteristics could include amount of wildlife seen, number and types of social encounters, campsite vegetation loss, or amount of litter seen (Watson, Williams, Roggenbuck, \& Daigle, 1992). Assessments of such aspects of visitor attitudes and preferences provide insight regarding visitor experiences. This section discusses early and later research pertaining to visitor attitudes and preferences, as well as how this research integrates with other wilderness visitor research.

Early attitudes and preferences research. Although research of visitor attitudes and preferences had not yet begun in earnest in the late 1950s, Dana (1957) argued that area managers are more likely to make wise decisions when they are familiar with public opinion and he urged policymakers to consider ways to ascertain such attitudes and preferences. A few years later, LaPage (1963) also confronted traditional approaches to research, arguing that the "demand for recreation can be seen to be an exceedingly complex human phenomenon involving the interaction of numerous individual and social values" (p. 35). Many studies conducted in the mid to late 1960s focused on an area's physical conditions (e.g. facilities or vegetation) and some aspect or combination of visitor preferences, expectations, or satisfactions.

Shafer and Burke (1965) administered 1,600 interviews over two weeks in four northeastern Pennsylvania State Parks: Hickory Run, Promised Land, Ricketts Glen, and 
Tobyhanna. The purpose of their study was to measure visitor preferences for outdoor recreation facilities and to determine if there is a relationship between user characteristics and facility preferences. All participants were categorized as campers and noncampers. Additionally, participants were classified by four visitor attributes: age, gender, family status, and population density of residence. Finally, participants were also classified by three visit attributes: travel distance, duration of stay, and group relationship. Analyses indicated that camper preferences differ from noncamper preferences for swimming areas, fireplaces, camping facilities, and campsite spacing. Only the noncamper group revealed significant preference differences related to user characteristics.

Frissell and Duncan (1965) conducted 33 interviews in the Quetico-Superior canoe country to determine participants' campsite preferences, as part of a larger study to determine the feasibility of increasing the number of established campsites. Interviews conducted at campsites, asked participants about the site they currently occupied, their trip, and satisfaction with their current campsite. The results indicated that approximately one-third of participants were satisfied, and that participants preferred island campsites that are located in pine stands. Additionally, the researchers concluded that campsite choice is frequently determined by convenience rather than preference.

Klukas and Duncan (1967) combined direct observation and interview methods to determine Itasca State Park visitor's vegetation preferences. Researchers conducted 600 camper interviews with the heads of families or group leaders and observed 280 vehicular visitor groups' reactions to four vegetatively different forest stands. Results indicated that participants prefer red and white pine vegetative cover, and that out-of-state visitor preferences differed from Minnesota resident's vegetative preferences. The researchers 
concluded that maintenance of the red and white pine forest stands should be a management priority.

Merriam and Ammons (1968) conducted a study of summer users in three preserved areas in Montana's northern Rocky Mountains: the Bob Marshall Wilderness, the Mission Mountain Primitive Area, and Glacier National Park. Researchers conducted 108 interviews with wilderness users and 49 interviews with campground users to determine visitors' expectations of and preferences for a wilderness experience. Researchers found that wilderness users expect wilderness areas to be difficult to access, free of roads, undeveloped, and sparsely populated; while, campground users only expect wilderness areas to have very few visitors. Similarly, wilderness visitors indicated that staying in the wilderness overnight was an important part of the wilderness experience; while, campground users indicated that staying overnight was not important to the wilderness experience.

Results of these early studies often reflected complex human phenomena, as researchers found connections between different user groups, activity aggregations, and different desires (Burch, 1964). Roggenbuck and Lucas (1987) contended that understanding visitor attitudes and preferences is particularly important when visitors are dissatisfied or are in conflict with one another. Manning (1999) stated that "[i]f a basic purpose of managing outdoor recreation is to provide satisfying experiences to visitors, then objective and systematically collected information is needed from visitors about what defines satisfying recreation experiences" (p. 281).

Later attitudes and preferences research. Empirical research of visitor attitudes and preferences has frequently uncovered a large and often conflicting range of reported 
attitudes and preferences. One of the more frequently studied concepts of visitor preferences is preferences for campsite conditions (e.g., Beardsley, 1967; Bumgardner, Waring, Legg, \& Goetz, 1988; Cordell \& James, 1972; Cordell \& Sykes, 1969; Frissell \& Duncan, 1965; Hancock, 1973; James \& Cordell, 1970; Knudson \& Curry, 1981; Lime, 1971; Love, 1964; Lucas, 1970; McEwen, 1986; Merriam \& Smith, 1974; Shafer \& Burke, 1965; Shafer \& Thompson, 1968). Manning (1999) indicated that while these studies often provide the majority of visitors' attitudes and preferences, there is usually "considerable diversity within the data" (p. 50).

Badger (1975) sampled 203 trail registrant user groups in the Rawah Wilderness to determine visitors' crowding preferences. The results indicated that visitors are willing to tolerate higher levels of crowding than they would actually like to experience. Likewise, Freimund and Cole (2001) found that in high-use wilderness areas visitors do not support use limits, at the same time the visitors also indicated that they encountered more people than preferred. Despite numerous studies on crowding and satisfaction in wilderness areas (Absher \& Lee, 1981; Alldredge, 1973; Brown \& Haas, 1980; Dorfman, 1979; Fisher \& Krutilla, 1972; Heberlein, Trent, \& Baumgartner, 1982; LaPage, 1963; Lee, 1975; Lime, 1970; Lucas, 1964a and b; Lucas \& Priddle, 1964; Manning, Lime, Freimund, \& Pitt, 1996; McConnell, 1977; Morgan, 1970; Price, 1977; Priddle, 1964; Schreyer \& Roggenbuck, 1978; Shelby, 1980 and 1981; Shelby \& Colvin, 1982; Shelby \& Neilson, 1976; Stankey, 1973; Takahashi \& Milano, 2004; Wagar, 1964), Cole (2001) stated that " $[\mathrm{t}] \mathrm{here}$ is still no empirical evidence that encountering more people than one prefers has a substantial adverse effect on the quality of most visitors' experiences" (p. $14)$. 
Schreyer and Roggenbuck (1978) administered 854 questionnaires to Dinosaur National Monument river recreationists to determine visitor experience expectation scales, wilderness attitude scales, and crowding preferences. Results revealed numerous user groups: day users, overnight users, commercial users, private users, educational users, high wildernists (has extensive previous wilderness experience), medium wildernists (has previous wilderness experience), and low wildernists (has little-to- no previous wilderness experience). Researchers found significant differences in expectations and attitudes between the different user groups. Additionally, analyses indicated that relationships exist between individual users' expectations, attitudes, and preferences.

Shelby, Danley, Gibbs, and Petersen (1982) studied user attitudes about permit allocation techniques for river runners in Hells Canyon and backpackers in Eagle Cap Wilderness and Mount Jefferson Wilderness. Area users were approached on-site and given a questionnaire to return by mail. The questionnaire addressed participants' attitudes about five specific permit systems: purchasing permits, advanced reservations, lottery, queuing, and merit. Analyses revealed that overall participants responded favorably to purchasing permits and advanced reservations; however, significant differences were found between river runners' and backpackers' attitudes towards lottery, queuing, and merit systems.

Watson et al. (1992) researched visitor preferences for wilderness conditions in three National Forest Wilderness Areas: Cohutta Wilderness, Caney Creek Wilderness, and Upland Island Wilderness. This study employed interviews and questionnaires to obtain participants' preferences for 19 wilderness condition items, including amount of 
litter, number of wild animals, and number of large groups seen during this trip.

Researchers found that visitor attitudes and preferences differ according to the wilderness study location.

Chavez (1997) studied San Jacinto Ranger District mountain bikers to determine their preferences for mountain biking in that area. The researcher administered a onepage, mini-questionnaire on-site and then followed up with a mailed questionnaire. Of 163 mountain bikers approached, 94 completed both the mini- and mailed questionnaires. Results indicated that most respondents have similar attitudes and preferences, agreeing with statements like "the type of mountain bike equipment I use means a lot to me" (p. 46). Analyses revealed significant differences between users' experience levels and attitudes about cleaning up after others, yielding to pedestrian/horse users, and seeking challenging terrain.

Graefe, Absher, Ye, and Nyaupane (2005) conducted multi-method visitor surveys at Shasta Lake and Trinity Lake to assess visitor expectations, preferences, and satisfaction. Through 789 interviews and 1,236 mailed questionnaires, four user groups were determined: onsite boaters, private houseboat permit holders, moorage customers, and rental customers. Visitor satisfaction was consistently high for all user groups, while visitor attitudes and preferences about possible management options greatly differed according to user groups.

Integration of attitudes and preferences research. These studies support Manning's (1999) claim that great variability exists between visitors' attitudes and preference by demonstrating that experience levels, user groups, study locale, and activity aggregations are related to participants' reported attitudes and preferences. Although 
such discrepancies between visitors' attitudes and preference may seem ambiguous, Wagar (1974) reflected that "outdoor recreation is primarily a psychological experience whose quality may depend as much (or more) on a person's expectations, belief systems, and prior experiences as on the physical condition of the area he visits" (p. 274). Further, Dorwart, Leung, and Moore (2004) argued that "what a person prefers in their outdoor recreation experience, the environment that they choose to be in, and the impacts that they notice within this experience, are all based on visitor perception," as “[p]erceptions...lead to preference judgments" (p. 29). In other words, visitor attitudes and preferences for a particular wilderness area may be determined by visitor perceptions of that wilderness.

\section{Visitor Perceptions}

Watson et al. (2000) explained that visitor perceptions offer researchers and area managers a clear indication of the problems that concern visitors. This indication has been provided through an understanding of "visitor perceptions of conditions... [their] reactions to perceived conditions... [their] opinions on current conditions, and how [they perceive conditions] to be changing over time" (p. 15). Dorwart et al. (2004) stressed that "what visitors notice during their visits to...wilderness areas affect their overall experience, [and as] visitors do in fact perceive various types of resource impacts...some may have serious effects on the quality of the visitors' experiences" (pp. 24, 29). Noe, Hammitt, and Bixler (1997) contended that area managers need to be aware of how visitors perceive area impacts and how these perceptions may impact the quality of a visitor's experience. This section discusses research pertaining to visitor perceptions of 
social and environmental impacts, as well as how this research integrates with other wilderness visitor research.

Research on perceptions of social impacts. Early studies on visitor perceptions found that perceptions are influenced by situations. Lee (1972) stated that recreational areas "might best be understood in terms of meanings assigned to them by particular sociocultural groups" (p. 68), finding that the "social setting was the key variable emphasizing changes in the physical context in which the action took place" (Noe et al., 1997, p. 325). Perception of crowding has been arguably the most researched social impact. Manning (1999) asserted that perception of crowding is affected by visitors' coping behaviors and normative definitions of crowding, as well as by researchers' conceptualizations and measurements of crowding.

The Outdoor Recreation Resources Review Commission (1962) study included a visitor survey of 24 nationwide outdoor recreation sites, which examined participants' perceptions of site crowding. Analyses revealed that while almost $20 \%$ of respondents perceived the site to be crowded, a similar number of respondents indicated that they would be satisfied with greater number of visitors in the area.

Lucas (1964a) conducted a visitor usage study in the Boundary Waters Canoe Area that included an item to determine participant perceptions of crowding. Results indicated that crowding perceptions are affected by user type, as $34 \%$ of paddling canoeists perceived some level of crowding, while $16 \%$ of motor canoeists and only $8 \%$ of motorboaters acknowledged crowding.

Knudson and Curry (1981) studied visitor perceptions of campground crowding in three campgrounds in two Indiana State Parks. Researchers found that respondents did 
not perceive crowding to affect their enjoyment of the camping experience. In fact, only $25 \%$ of participants perceived the campgrounds to be crowded, despite significant crowding.

Manning (1999) indicated that a single-item, 9-point scale to determine measures of crowding has frequently been implemented by researchers, allowing for comparison of studies. Shelby, Vaske, and Heberlein (1989) conducted a comparison of 35 studies that implemented this 9-point perceived crowding scale, combining data from over 59 areas and more than 17,000 participants. These results revealed that some participants in all studies perceived levels of crowding as the percentage of participants who perceived levels of crowding ranged from $12 \%$ to $100 \%$, with a mean of $57 \%$. The researchers discovered that crowding is affected by time, area resource availability, visitor accessibility and convenience, and management strategies.

Tarrant (1999) conducted a study of Nantahala River recreational boaters' perceptions of crowding to assess the variability of the 9-point perceived crowding scale (Manning, 1999). This study considered the effect of the method of administration, response time, and location within the recreational area on self-reported levels of crowding. Analysis revealed that mail-back methods return higher levels of perceived crowding than on-site measurements, and that levels of perceived crowding do vary by location within a recreational area.

Kuentzel and Heberlein (2003) conducted a longitudinal visitor usage study at the Apostle Islands National Lakeshore to research relationships between perceived crowding and visitor characteristics, behaviors, and normative standards. They discovered that while annual visitation more than doubled from 1975 to 1985 , 
perceptions of crowding had decreased by 1985 and participants indicated an increased preference for encounters with other visitors. As visitations continued to increase from 1985 to 1997, perceptions of crowding increased, while preferences for encounters did not change. Researchers concluded that continual monitoring of perceived crowding and norms is needed for management policy.

Grieser, Dawson, and Schuster (2006) administered a visitor usage study in the Mohonk Preserve to identify visitor perceptions of crowding. One hundred interviews and photographic visual preference surveys were conducted in both low and high usage areas of the preserve. Results indicated that over $50 \%$ of participants had perceived the preserve to be crowded at least once, the majority of those participants also engaged in some form of coping behavior. The researchers also found that perception of crowding was affected by demographics and activity aggregations.

Research on perceptions of environmental impacts. Behan (1974) argued that the quality of visitor experiences are not determined by absolute characteristics of the land but rather by the visitor's expectations and perceptions. Early research in visitor perceptions documented little visitor awareness of environmental impacts due to recreation (Lucas, 1979). This apparent deficiency in visitor awareness may be attributed to the fact that early outdoor recreation research rarely studied visitors' perceptions of environmental impacts (Hillery, Nancarrow, Griffin, \& Syme, 2001). Dorwart et al. (2004) indicated that the lack of research makes it difficult to determine visitors' awareness of environmental impacts.

Recent empirical research has focused on visitor perceptions of environmental impacts and also the effect such perceptions may have on visitors (Alessa, Bennett, \& 
Kliskey, 2003; Farrell, Hall, \& White, 2001; Floyd, Jang, \& Noe, 1997; Hillery, et al., 2001; Noe et al., 1997; Priskin, 2003; White, Hall, \& Farrell, 2001). Noe et al. (1997) believed that "[s]ituational definitions affect actions and may be involved in how park users reject or accept impacts" (p. 326).

White et al. (2001) found that while visitors noted garbage, litter, human waste, and lack of privacy when camping, these negative perceptions often did not effect visitors' campsite selection. At the same time, visitors indicated that they would accept negative recreational impacts at a site for greater functional amenities, perceiving the more desirable campsites to have fire rings, be near water, and bare of vegetation.

Noe et al. (1997) conducted visitor perception studies in three southeastern National Parks: Blue Ridge Parkway, Chattahoochee River National Recreation Area, and Chickamauga and Chattanooga National Military Park. Mailed questionnaires were returned by 971 respondents. Researchers found that respondent acceptance of area impacts was affected by the location and situational conditions surrounding the impact. For example, results indicated that "litter was somewhat more tolerable...if found in public areas (roadsides, parking areas, restrooms) than if located in natural areas along trails and streams" (p. 329).

Hillery et al. (2001) studied visitor perceptions of environmental impacts at 10 sites in Central Australia. Researchers measured the extent and intensity of nine environmental impacts at each of the sites, and interviewed 324 visitors to determine their perceptions of the extent and intensity of environmental impacts. Researchers found that visitors' perceptions of recreational impacts increased in locations where there were 
greater numbers of tourist and impacts, but that visitors generally could not perceive differences in environmental impact amongst the 10 sites.

Lynn and Brown (2003) studied the effects of environmental impacts on hikers' experiences on the Starkey Hill Interpretive Trail in Toronto, Canada. This study used photographs that depicted trail impacts, to determine if the hikers would perceive various impacts and if the perceptions of those impacts would affect their experience. Researchers found that litter, fire rings, and tree and plant damage, as well as trail extension, widening, and erosion were perceived by the hikers. The perceptions of litter, fire rings, and tree and plant damage had a greater negative effect on their experience, while trail extension, widening, and erosion had a moderately negative experience effect. Priskin (2003) studied visitors to the Central Coast Region of Western Australia and found that perceptions of the environmental damage caused by certain recreational activities varied by gender, age, education level, nationality, and activity group. This study emphasizes the existing relationship between visitor perceptions and visit and visitor attributes.

Dorwart et al. (2004) suggested that "[i]nformation on visitor perceptions may also be valuable when setting maintenance and management priorities for allocating scarce funds and resources” (p. 24). Meanwhile, Newsome, Moore, \& Dowling (2002) found that such visitor perceptions may not only be critical in identifying resource and social impact indicators, but may also be important in setting standards of quality for these indicators. 


\section{Summary}

As wilderness research has continued to reveal connections between visit and visitor attributes, visitor attitudes and preferences, and visitor perceptions, Graefe et al. (2005) recommended multi-method approaches that can both measure and examine how wilderness area users perceive an area's current conditions. Freimund and Cole (2001) promoted "combining the strengths of diverse social sciences such as cultural geography, sociology, political science, and social and environmental psychology" to expand insight and understanding of the multifaceted issues of recreation use (p. 8). In addition to expanding the focus of research, Cole (2001) recommended broadening the population of interest in order to include both users' and nonusers' needs and interests in the focus of wilderness studies and management policy recommendations. Research of wilderness use and wilderness users, specifically considering visit and visitor attributes, visitor attitudes and preferences, and visitor perceptions, has indicated that maintaining quality visitor experiences and upholding the ecological integrity of protected areas requires comprehensive wilderness use and visitor information to be both collected and considered during the formation of management policy. 


\section{CHAPTER 3}

\section{METHODS}

Wilderness use has provided critical information for the formation and evaluation

of area management. Roggenbuck and Lucas (1987) indicated that such use may increase the value of visitor experiences and effectiveness of wilderness management. This study examines visitor attributes, attitudes, and visitor perceptions of social and environmental impacts at Mount San Jacinto State Park. This chapter presents the methods used to conduct two visitor use surveys in Mount San Jacinto State Park.

\section{Study Locale}

Mount San Jacinto State Park hosts more than 400,000 visitors per year and offers an array of outdoor recreation opportunities, ranging from developed camping, backpacking, skiing, wildlife viewing, guided hikes, horseback trails, nature trails, and access to the Pacific Crest Trail. Long Valley, accessible by the Palm Springs Aerial Tramway or by trail from Idyllwild, serves as the park's primary access point. The park's trail system converges in Long Valley, providing opportunities for day hiking and backpacking. (Figure 1). Within Long Valley, day users can access the self-guided Nature and Desert View Trails. Hikers may obtain a day or overnight use permit for the wilderness hiking system at the Long Valley Ranger Station. The wilderness is accessed by heading west to Round Valley where visitors can hike up the Round Valley Loop, Willow Creek Trail, Wellman Divide, Trail to San Jacinto Peak, or the Pacific Crest Trail. Marion Mountain Trail and Deer Springs Trail provide access to Long Valley from Idyllwild, while the Skyline Ridge Route offers access from Palm Springs. 


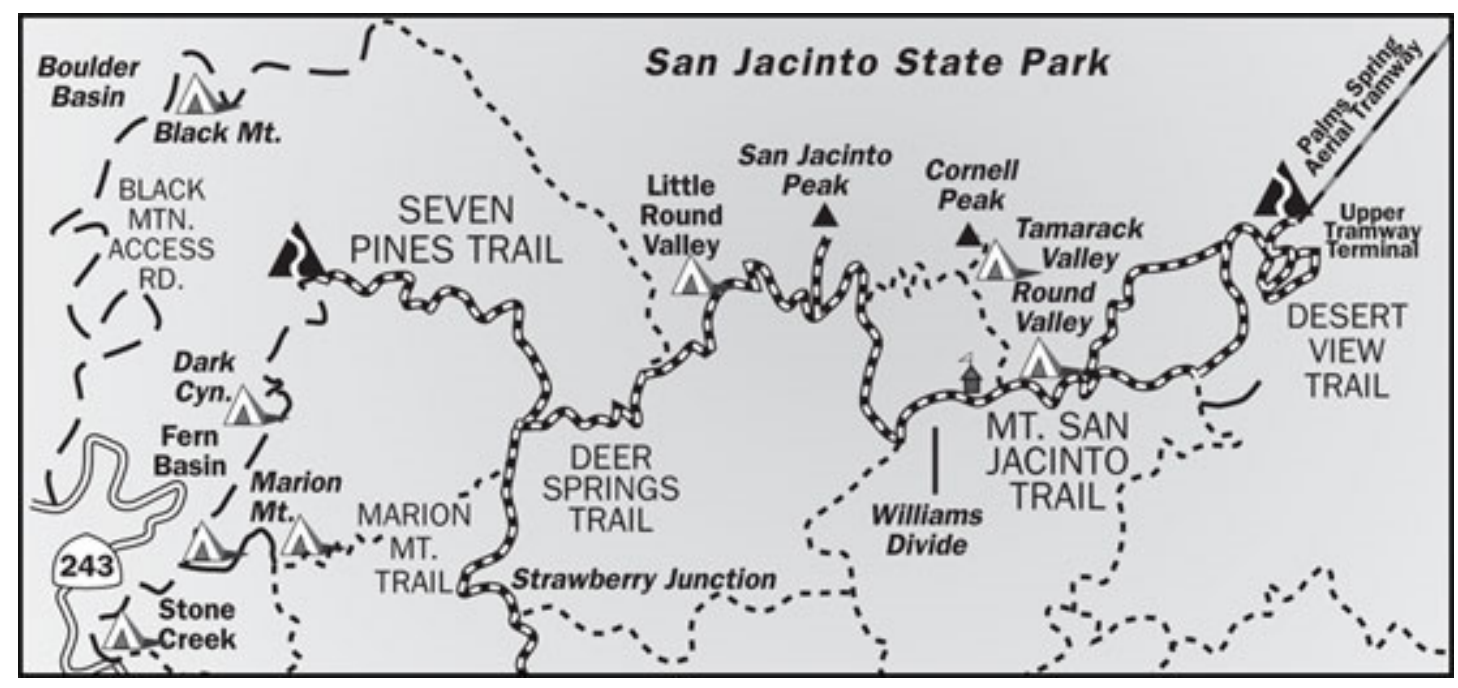

Figure 1. San Jacinto Peak Trail Map, Mount San Jacinto State Park (2007).

Note. Copyright The Trailmaster, Inc., 2007.

\section{Description of Subjects}

The population of interest for this study was limited to 2008 summer-weekend Mount San Jacinto State Park Long Valley and Wilderness Area visitors. During the preselected sampling times, visitors were contacted by a research assistant who requested that a member from each visitor group entering Long Valley or the Long Valley Ranger Station participate in the study.

Four types of visitors were of interest for this study: Long Valley day users, wilderness day use hikers, San Jacinto Peak users, and wilderness campers. Long Valley day users were visitors who enter the park by the Palm Springs Aerial Tramway, do not access the wilderness area, and leave the park on the same day. Wilderness day use hikers were visitors who enter the park by the Palm Springs Aerial Tramway, access the wilderness for hiking, and leave the park on the same day. San Jacinto Peak users were visitors that hike to San Jacinto Peak during their visit. Wilderness campers were visitors who spend one or more nights in a wilderness area campground before leaving the park. 


\section{Description of Instrument}

Two questionnaires were used in this study, one for Long Valley visitors (Appendix A) and one for Wilderness area visitors (Appendix B). The survey was pilot tested in Mount San Jacinto State Park during the last weekend of June 2008, as well as reviewed by personnel at Mount San Jacinto State Park. The modifications made to the visitor surveys based on this feedback, included revisions of question wording, adjustment to annual income range, addition of a question to determine how visitors had heard about Mount San Jacinto State Park, and addition of visitor activity, crowding, smoking, and environmental impact items.

The Long Valley Visitor Survey consisted of 20 questions, while the Wilderness Visitor Survey consisted of 30 questions. Each question specifically addressed one of the seven research questions: 1) What are Mount San Jacinto State Park visit attributes?

2) What are Mount San Jacinto State Park visitors' attributes? 3) What are Mount San Jacinto State Park visitors' attitudes and preferences towards crowding, displacement in the park, park safety, and management policies? 4) What are Mount San Jacinto State Park visitors' perceptions of social and environmental impacts? 5) Does Mount San Jacinto State Park visitor activity participation differ by user type or by residency? 6) Do Mount San Jacinto State Park visitors' attitudes and preferences differ by user type, gender, residency, number of nights spent in the wilderness, number of miles hiked in the wilderness, number of total previous park visits, number of previous 2008 park visits, group size, or by number of hours spent in the wilderness? 7) Do Mount San Jacinto State Park visitors' perceptions of social and environmental impacts differ by user type, 
gender, residency, number of nights spent in the wilderness, number of miles hiked in the wilderness, income levels, group size, or by hours spent in the wilderness?

Long Valley Visitor Survey. Of the 20 questions, 15 consider visit and visitor attributes. Questions 1, 2, 3, and 6 are adapted from Hendricks, Love, and Hamilton (2003) and Hendricks, Hamilton, and Bohlken (2007) to measure subjects' visit attributes. They were modified based on the Watson et al. (2000) definition of visit attributes. These questions answer length of stay, activity participation, travel methods, and group size. Questions 4, 5, 11, 12, 13, 14, 15, 16, 17, 18, and 19 are also adapted from Hendricks et al. (2003) and Hendricks et al. (2007) to measure subjects' visitor attributes. They were modified based on the Watson et al. (2000) definition of visitor attributes. These questions discuss subjects' past experiences in Mount San Jacinto State Park, gender, marital status, age, education, annual income, race, and residency at the national, state, and county levels.

Question eight addresses subjects' attitudes and preferences. This Likert-type scale was adapted from Graefe et al. (2005). It was modified based on the Watson et al. (2000) definition of visitor attitudes and preferences. This 6-item question employs a 4-point scale, 1 being "strongly disagree" and 4 being "strongly agree" with and option for “don't know," to determine subjects' attitudes and preferences about the adequacy of ranger patrol in the park, park safety, and crowding and displacement in the park.

The remaining three questions address subjects' perceptions of social and environmental impacts in the park and were modified based on Watson et al. (2000) definition of visitor perceptions. Question seven measures subjects' perceptions of crowding using a single-item, 9-point scale, where responses of three or greater indicate 
that subjects perceive some degree of crowding (Manning, 1999). Question nine is a Likert-type scale, adapted from Graefe et al. (2005). This 8-item question employs a 4-point scale, 1 being "not a problem" and 4 being "big problem" with an option for "not applicable," to determine how much of a problem subjects perceive litter, noise and behavior of other visitors, crowding, large groups, restroom cleanliness, and smoking to be in the park. Question 10 is adapted from Cole (2001) and asks subjects to indicate which of 11 conditions (See Appendix C) they noticed in the park, including worn trails, vegetation loss, and people in marked fragile areas.

Wilderness Visitor Survey. Of the 30 questions, 24 consider visit and visitor attributes. Questions 1, 2, 3, 6, 7, 8, 9, 10, 11, 12, 13, 14, and 15 are adapted from Hendricks et al. (2003) and Hendricks et al. (2007) to measure subjects' visit attributes. They were modified based on the Watson et al. (2000) definition of visit attributes. These questions answer length of stay, activity participation, travel methods, and group size. Questions 4, 5, 21, 22, 23, 24, 25, 26, 27, 28, and 29 are also adapted from Hendricks et al. (2003) and Hendricks et al. (2007) to measure subjects' visitor attributes. They were modified based on the Watson et al. (2000) definition of visitor attributes. These questions discuss subjects' past experiences in Mount San Jacinto State Park, gender, marital status, age, education, annual income, race, and residency at the national, state, and county levels.

Two questions address subjects' attitudes and preferences. Question 17 is a Likert-type Scale that was adapted from Graefe et al. (2005). It was modified based on the Watson et al. (2000) definition of visitor attitudes and preferences. This 8-item question employs a 4-point scale, 1 being "strongly disagree" and 4 being "strongly 
agree" with an option for "don't know," to determine subjects' attitudes and preferences about the adequacy of ranger patrol in the park, park safety, crowding and displacement in the park, and campsite reservations and availability. Question 20 is a partially closeended question that asks subjects about their attitude towards the current capacity limits for wilderness camping permits and their preferences for how many permits should be issued daily.

The remaining three questions address subjects' perceptions of social and environmental impacts in the park and were modified based on the Watson et al. (2000) definition of visitor perceptions. Question 16 measures subjects' perceptions of crowding using a single-item, 9-point scale, where responses of three or greater indicate that subjects perceive some degree of crowding (Manning, 1999). Question 18 is a Likerttype Scale, matrix question adapted from Graefe et al. (2005). This 16-item question employs a 4-point scale, 1 being "not a problem" and 4 being "big problem" with an option for "not applicable," to determine how much of a problem subjects perceive litter, noise and behavior of other visitors, crowding, large groups, restroom cleanliness, illegal campfires, human waste, locating the trail to the top of the peak, and smoking to be in the park. Question 19 is adapted from Cole (2001) and asks subjects to indicate which of 14 conditions (See Appendix C) they noticed in the park, which include: vegetation loss at campsites, erosion at campsites, and tree root exposure at campsites.

Both questionnaires included an introduction that was orally administered to subjects, as well as individual question instructions to guide research assistants in administering the survey. The introduction established the research assistant as a California Polytechnic State University employee working on behalf of Mount San 
Jacinto State Park and asks for visitors' voluntary and anonymous participation. These questionnaires contained a number of variables to determine visit and visitor attributes, visitor attitudes and preferences, and visitor perceptions. The questionnaires were created using Dobloo software and downloaded onto two Compaq Ipaq PDAs.

\section{Study Procedures}

In order to better understand Mount San Jacinto State Park visitors, surveys were conducted at two predetermined points within the 14,000-acre park, one at Long Valley and one within the Wilderness Area. Four weekends during the months of July, August, and September 2008 were randomly selected and probability sampling was employed to obtain a sample that represented visitors to Mount San Jacinto State Park. During each selected weekend research was conducted over eight randomly selected contact periods that spanned from Friday to Sunday, and in two randomly assigned locations: the entrance to Long Valley and adjacent to the Long Valley Ranger Station. Trained interviewers contacted park visitors. If visitors agreed to participate, researchers read participants an informed consent statement, advising subjects that participation was voluntary, their responses were anonymous, participation posed no risks, participation provided an opportunity to assist Mount San Jacinto State Park in better serving park visitors, and contact sources for obtaining more information about the study and the California Polytechnic State University Human Subjects Review Committee. The informed consent statement was approved by California Polytechnic State University's Human Subjects Review Committee (Appendix C). Researchers used Compaq's Ipaq PDA@ (2006) to perform the interviews and to collect data. They read each question aloud and recorded participant responses. If the research assistants approached two or 
more visitors in a group, the researchers requested participation from the visitor who was 18 or older and whose birthday was closest to that day.

Data Analysis

Using Dobloo@ (2008) software, each survey was recorded into a research assistant's Compaq handheld computer. These surveys were uploaded from the Compaq unit to Dobloo's internet-based, virtual storage. Once data collection was completed, the data were downloaded as two separate files, Long Valley Visitor Survey and Wilderness Visitor Survey, from the virtual storage into Excel databases. A third database was created that combined information from both Mount San Jacinto State Park Visitor Surveys. The final step was to transfer all three databases to the Statistical Package for the Social Sciences@ (2008) for data analysis.

Visit and visitor attributes. Data collected on visit and visitor attributes were analyzed using descriptive statistics. Mean, range, and standard deviation were calculated on continuous variables, including number of people in subject's group, number of hours the subject spends in the Wilderness Area, number of nights the subject spends in the Wilderness Area, total miles the subject hikes in the Wilderness Area, subject's age, and subject's education level. Range, mean, median, and mode were calculated for number of times subject has visited Mount San Jacinto State Park and number of times subject has visited Mount San Jacinto State Park in 2008. Frequencies were calculated for nominal and ordinal variables, including subject's trip description, how the subject reached the park entrance, activities the subject participated in, day and overnight users, wilderness campsites used, possession of day use permit, possession of camping permit, peak users, trails hiked, gender, marital status, income, ethnicity, and 
national, state, and county residency. Tests were not conducted for variables with cell sizes less than 5 .

Visitor attitudes and preferences. Data collected on visitor attitudes and preferences were analyzed using descriptive statistics. Both surveys used a Likert-type scale to determine subjects' attitudes and preferences. The data from these questions were analyzed for the mean, range, and standard deviation for each of the items (six items for the Long Valley Visitor Survey and eight items for the Wilderness Visitor Survey). Additionally, the data were analyzed by frequency for subjects that responded "don't know." The Wilderness Visitor Survey included a question to determine subject's attitudes and preferences about the camping permit capacity limits. This question was analyzed for the frequency of "yes," “no," and “don't know” responses. Spearman's Rank Correlation Coefficient tests were conducted to look for relationships between visitor attitudes and preferences and the following visit and visitor attributes: number of nights spent in the wilderness, numbers of miles hiked in the wilderness, total number of previous park visits, number of previous park visits in 2008, group size, and hours spent in the wilderness. Results from these tests are measured using rho $\left(\mathrm{R}_{\mathrm{s}}\right)$. These tests were run at .05 significance levels. This non-parametric test measures the linear relationship between two variables, and is analogous to the parametric linear regression test. Tests were not conducted for variables with cell sizes less than 5.

Visitor perceptions. Data collected on visitor perceptions were analyzed using descriptive statistics. Similar to the visitor attitudes and preferences, both surveys used a Likert-type scale to determine subjects' perceptions of problems in the park. The data from these questions were analyzed for the mean, range, and standard deviation of each 
of the items (eight items for the Long Valley Visitor Survey and 16 items for the Wilderness Visitor Survey). Again, frequencies were calculated for "not applicable" responses. Both surveys used a 9-point scale to determine subjects' perceptions of crowding. The data from these questions were analyzed for the mean, range, and standard deviation. The subjects were asked to indicate which conditions they noticed in the park. The data from these questions were analyzed for the frequency and percentage of each of the conditions (11 items for the Long Valley Visitor Survey and 14 items for the Wilderness Visitor Survey). Spearman's Rank Correlation Coefficient tests were conducted to look for relationships between perceptions and the following visit and visitor attributes: number of nights spent in the wilderness, numbers of miles hiked in the wilderness, income level, group size, and hours spent in the wilderness,. These tests were run at .05 significance levels. Tests were not conducted for variables with cell sizes less than 5 .

Relationships between visit and visitor attributes, visitor attitudes and preferences, and visitor perceptions. The final method of analysis looked at relationships between visit and visitor attributes, visitor attitudes and preferences, and visitor perceptions. Mann-Whitney U tests were conducted to determine differences between attitudes and preferences by user type, gender and residency, as well as visitor perceptions by user type, gender, and residency. These tests were run at .05 significance levels. This non-parametric test assesses whether two independent samples come from the same distribution, and is analogous to the parametric two-sample T-Test. Overall mean score, mean score ranks, standard deviations, and p-values are presented for these test results. Kruskal-Wallis one-way analysis of variance was conducted to look for 
relationships between attitudes and preferences by state, national, and international residency, as well as visitor perceptions by residency. This test was run at 05 significance levels. This non-parametric test assesses the equality of population medians among groups, and is analogous to the parametric ANOVA test. Pearson's chi-square tests were conducted to look for differences between activity and user type, gender, and residency; and conditions noticed by user type, gender, and residency. These tests were run at .05 significance levels. Spearman's Rank Correlation Coefficient tests were conducted to look for relationships between attitudes and preferences and group size, number of previous park visits, number of previous park visits in 2008, number of hours spent in the park, number of nights spent in the park, number of miles hiked, age, education level, and income level. These tests were run at .05 significance levels. Tests were not conducted for variables with cell sizes less than 5.

The following chapter will present the results of this data analysis. 


\section{CHAPTER 4}

\section{RESULTS}

This chapter presents results from a study of visit and visitor attributes, visitor attitudes and preferences, and visitor perceptions of social and environmental impacts at Mount San Jacinto State Park. This chapter presents the results from two visitor use surveys in Mount San Jacinto State Park.

\section{Visitor Attributes}

Contacts with 398 visitors at Mount San Jacinto State Park resulted in 378 subjects (providing usable surveys from $94.97 \%$ contacts with visitors). One hundred twenty-two subjects were wilderness visitors (32.3\%) and 256 (67.7\%) were Long Valley visitors. Most subjects were male (63.8\%), married (55.9\%), and white (79.9\%) or Hispanic/Latino (10.5\%) (Table 1). The average age was approximately 45 years old. The age range was 19 to 84 years old. Most subjects had completed some college education (85.4\%) (Table 2), with highest education level ranging from 1 to 22 years. The subjects reported fairly high levels of income as $42.4 \%$ of subjects indicated annual household incomes of $\$ 100,000$ or greater (Table 3). Approximately $37 \%$ of the subjects had an annual household income below $\$ 80,000$. The majority of subjects lived in California (72.1\%), with $93.0 \%$ of California residents residing in five counties (Table 4). Other subjects lived both out-of-state (16.6\%) (Table 5) and internationally (11.3\%) (Table 6). The most frequently reported way subjects obtained information about the park was through friends or family (43.8\%), followed by word of mouth (14.2\%) and the Palm Springs Aerial Tramway (11.8\%) (Table 7). 
Table 1

Race/Ethnicity

\begin{tabular}{lccc}
\hline Race/Ethnicity & Frequency & Percentage & Cumulative \% \\
White & 298 & 80.1 & 80.1 \\
Black or African American & 6 & 1.6 & 81.7 \\
Hispanic/Latino & 39 & 10.5 & 92.2 \\
Asian & 12 & 3.2 & 95.4 \\
American Indian or Alaskan Native & 2 & 0.5 & 96.0 \\
Chinese & 1 & 0.3 & 96.2 \\
Filipino & 2 & 0.5 & 95.8 \\
Japanese & 1 & 0.3 & 97.0 \\
Korean & 1 & 0.3 & 97.3 \\
Middle Eastern & 1 & 0.3 & 97.6 \\
Native Hawaiian or other Pacific Islander & 1 & 0.3 & 97.8 \\
Taiwanese & 3 & 1.3 & 100.00 \\
European & 5 & & 98.7 \\
\hline
\end{tabular}

Note. $\mathrm{n}=372$

Table 2 
Highest Education Level

\begin{tabular}{lccc}
\hline Education & Frequency & Percentage & Cumulative \% \\
Post Graduate (17-22 years) & 140 & 37.3 & 37.3 \\
College (13-16 years) & 187 & 49.7 & 87.0 \\
Completed high school (12 years) & 45 & 12.0 & 99.0 \\
Some high school (9-11 years) & 2 & 0.5 & 99.5 \\
Completed middle school (6-8 years) & 0 & 0.0 & 99.5 \\
Some elementary (1-5 years) & 2 & 0.5 & 100.0 \\
\hline
\end{tabular}

Note. $\mathrm{n}=376$

Table 3

Annual Household Income

\begin{tabular}{lccc}
\hline Income & Frequency & Percentage & Cumulative \% \\
Greater than $\$ 200,000$ & 23 & 8.1 & 8.1 \\
$\$ 180,001-200,000$ & 9 & 3.2 & 11.3 \\
$\$ 160,001-180,000$ & 10 & 3.5 & 14.8 \\
$\$ 140,001-160,000$ & 15 & 5.3 & 20.1 \\
$\$ 120,001-140,000$ & 24 & 8.5 & 28.6 \\
$\$ 100,001-120,000$ & 39 & 13.8 & 42.4 \\
$\$ 80,001-100,000$ & 58 & 20.5 & 62.9 \\
$\$ 60,001-80,000$ & 54 & 19.1 & 82.0 \\
$\$ 40,000-60,000$ & 37 & 13.1 & 95.1 \\
Less than $\$ 40,000$ & 14 & 4.9 & 100.0 \\
\hline
\end{tabular}

Note. $\mathrm{n}=283$

Visit Attributes 
Long Valley and wilderness subjects provided answers to questions about their visit attributes. The average group size was 3.57 individuals. Group size ranged from 1 to 40 . The majority of subjects hiked along trails within the park $(n=316,83.8 \%)$ rather than hiking to San Jacinto Peak $(n=60,15.9 \%)$. Only four subjects $(1.1 \%)$ entered Long Valley by hiking from Idyllwild, while the majority accessed the park through the Palm Springs Aerial Tramway $(n=374,98.9 \%)$. Subjects have previously been to the park an average range of 1-600 visits, and in 2008 they visited the park a range of 0-100 times. The skewed ranges, due to high outliers, suggest that the mode and median may provide the most accurate picture of average previous visits. The median total previous number of visits was two, with the mode being one, while the mean number of total previous number of visits was 15.13 . The median and mode of previous 2008 visits was one, while the mean was 3.74 .

Subjects that entered the wilderness during their current visit provided visit attribute information about that experience. The majority of subjects who entered the wilderness area did not stay overnight $(n=93,76.3 \%)$. The average number of hours spent in the wilderness area was 4.68 hours. The majority of day use wilderness area subjects $(n=90,96.8 \%)$ reported obtaining the required day use permit. Three subjects (3.2\%) indicated that they did not acquire the required day use permit. Similarly, all but one overnight wilderness area subject (3.4\%) reported obtaining the required camping permit $(n=28,96.6 \%)$. The average number of nights spent in the wilderness area was 1.78. Round Valley was the campsite most subjects reported using (Figure 2). Of 122 wilderness area users, $49(40.2 \%)$ planned to hike to San Jacinto Peak sometime during their visit. The Round Valley Loop was the trail most wilderness area users (88.9\%) 
reported using (Figure 3). Subjects reported hiking an average of 8.9 miles during their visit to the wilderness area.

Participation in recreational activities during the park visit was also of interest (Table 8). Activities most frequently reported were hiking (95.0\%), photography (73.8\%), wildlife viewing (44.7\%), visiting the gift shop (44.4\%), bird watching (42.9\%), visiting the visitor center (34.9\%), and eating at the snack bar (34.7\%). Activities reported by few subjects included bouldering (7.4\%) and nature led activities (0.8\%).

Pearson's chi-square test was conducted to look for differences in activity participation by user type (Table 9) and residency (Table 10). Long Valley users were more likely to eat at the restaurant $\left(x^{2}=15.086, d f=2, p\right.$-value $\left.=.001\right)$, shop at the gift shop $\left(x^{2}=33.704, d f=1, p\right.$-value $\left.=.000\right)$, visit the visitor center $\left(x^{2}=24.854, d f=1, p-\right.$ value $\left.=.000\right)$, view wildlife $\left(x^{2}=15.071, d f=1, p\right.$-value $\left.=.000\right)$, bird watch $\left(x^{2}=14.767, d f=1, p-\right.$ value $=.000)$, and participate in photography $\left(\mathrm{x}^{2}=20.393, \mathrm{df}=1, \mathrm{p}\right.$-value $\left.=.000\right)$; while, wilderness users were more likely to picnic $\left(\mathrm{x}^{2}=11.444, \mathrm{df}=1\right.$, $\mathrm{p}$-value $\left.=.001\right)$. NonCalifornian, United States residents were significantly more likely to participate in shopping at the gift shop $\left(\mathrm{x}^{2}=15.277, \mathrm{df}=2, \mathrm{p}\right.$-value $\left.=.000\right)$, visiting the visitor center $\left(\mathrm{x}^{2}=8.704, \mathrm{df}=2, \mathrm{p}\right.$-value $\left.=.013\right)$, and wildlife viewing $\left(\mathrm{x}^{2}=7.739, \mathrm{df}=2, \mathrm{p}\right.$-value $\left.=.021\right)$. International residents were significantly more likely to participate in photography $\left(x^{2}=17.555, \mathrm{df}=2, \mathrm{p}-\right.$ value $\left.=.000\right)$.

Table 4 


\section{California County Residence}

\begin{tabular}{lccc}
\hline County & Frequency & Percentage & Cumulative \% \\
Riverside & 102 & 37.9 & 37.9 \\
Los Angeles & 62 & 23.0 & 60.9 \\
San Diego & 35 & 13.0 & 73.9 \\
Orange & 34 & 12.6 & 86.5 \\
San Bernardino & 19 & 7.1 & 93.6 \\
Ventura & 5 & 1.9 & 95.5 \\
San Francisco & 3 & 1.1 & 96.6 \\
San Mateo & 2 & 0.7 & 97.3 \\
Sacramento & 2 & 0.7 & 98 \\
Santa Barbara & 1 & 0.4 & 98.4 \\
Santa Clara & 1 & 0.4 & 98.8 \\
Tulare & 1 & 0.4 & 99.2 \\
Imperial & 1 & 0.4 & 99.6 \\
Monterey & 1 & 0.4 & 100.0 \\
\hline
\end{tabular}

Note. $\mathrm{n}=269$

Table 5 
State of Residence

\begin{tabular}{|c|c|c|c|}
\hline State & Frequency & Percentage & Cumulative \% \\
\hline Arizona & 11 & 18.3 & 18.3 \\
\hline Colorado & 1 & 1.7 & 20.0 \\
\hline Delaware & 1 & 1.7 & 21.7 \\
\hline Florida & 5 & 8.2 & 29.9 \\
\hline Georgia & 1 & 1.7 & 31.6 \\
\hline Idaho & 3 & 5.0 & 36.6 \\
\hline Illinois & 3 & 5.0 & 41.6 \\
\hline Indiana & 3 & 5.0 & 46.6 \\
\hline Kentucky & 2 & 3.3 & 49.9 \\
\hline Louisiana & 2 & 3.3 & 53.2 \\
\hline Maryland & 4 & 6.7 & 59.9 \\
\hline Massachusetts & 1 & 1.7 & 61.6 \\
\hline Missouri & 1 & 1.7 & 63.3 \\
\hline Nevada & 1 & 1.7 & 65.0 \\
\hline New Jersey & 1 & 1.7 & 66.7 \\
\hline New Mexico & 1 & 1.7 & 68.4 \\
\hline New York & 3 & 5.0 & 73.4 \\
\hline North Carolina & 1 & 1.7 & 75.1 \\
\hline Ohio & 1 & 1.7 & 76.8 \\
\hline Pennsylvania & 5 & 8.2 & 85.0 \\
\hline
\end{tabular}

Table 5 continued 
State Frequency Percentage Cumulative \%

Texas

6

10.0

95.0

Utah

1

1.7

96.7

Washington

2

3.3

100

Note. $\mathrm{n}=60$

Table 6

Nationality

Nation Frequency Percentage Cumulative \%

\begin{tabular}{|c|c|c|c|}
\hline Australia & 2 & 4.7 & 4.7 \\
\hline Belgium & 1 & 2.3 & 7.0 \\
\hline Brazil & 1 & 2.3 & 9.3 \\
\hline Britain/England & 11 & 25.6 & 34.9 \\
\hline Canada & 3 & 7.0 & 41.9 \\
\hline Denmark & 1 & 2.3 & 44.2 \\
\hline France & 3 & 7.0 & 51.2 \\
\hline Germany & 10 & 23.2 & 74.4 \\
\hline Holland & 4 & 9.3 & 83.7 \\
\hline Israel & 1 & 2.3 & 86.0 \\
\hline Netherlands & 3 & 7.0 & 93.0 \\
\hline Switzerland & 1 & 2.3 & 95.3 \\
\hline Taiwan & 2 & 4.7 & 100.0 \\
\hline
\end{tabular}

Note. $\mathrm{n}=43$

Table 7

How Subjects Obtained Information about the Park 


\begin{tabular}{lccc} 
Source & Frequency & Percentage & Cumulative \% \\
Friends or family & 126 & 43.7 & 43.7 \\
Word of mouth & 41 & 14.2 & 57.9 \\
Palm Springs Aerial Tramway & 34 & 11.8 & 69.7 \\
State Parks website & 23 & 8.0 & 77.7 \\
San Jacinto State Park brochure & 15 & 5.2 & 82.9 \\
Other & 14 & 4.9 & 87.8 \\
At a hotel & 12 & 4.2 & 92.0 \\
Book & 11 & 3.8 & 95.8 \\
Travel/hiking magazine & 8 & 2.8 & 98.6 \\
Travel agent & 2 & 0.7 & 99.3 \\
Newspaper & 2 & 0.7 & 100.0 \\
\hline
\end{tabular}




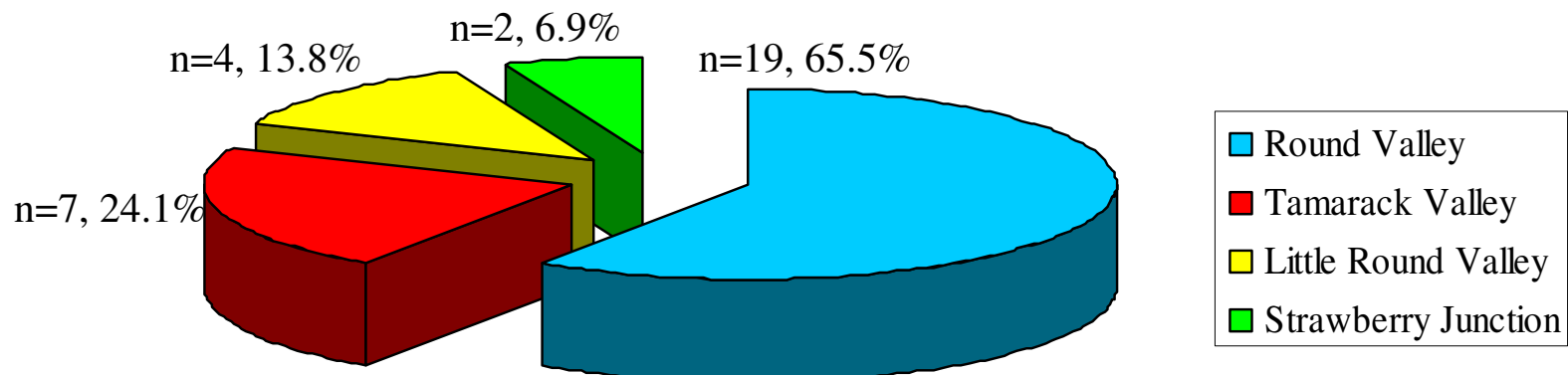

Figure 2. Campsites used

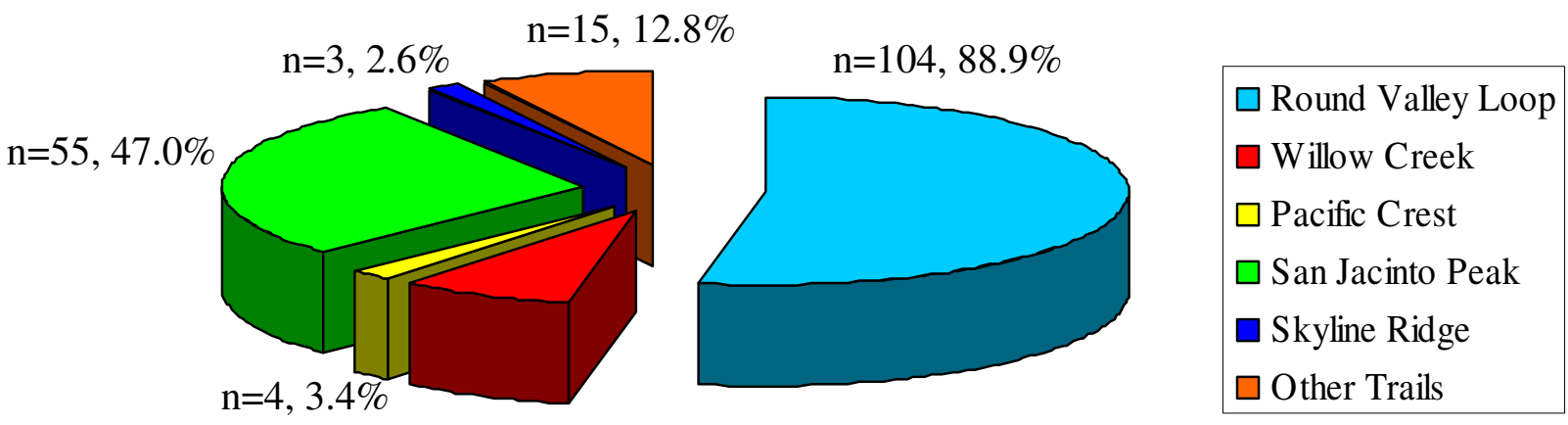

$$
\mathrm{n}=15,12.8 \%
$$

Figure 3. Trails used 
Table 8

Recreational Activities

\begin{tabular}{lcc}
\hline Activity & Frequency & Percentage \\
Photography & 279 & 73.8 \\
Wildlife viewing & 169 & 44.7 \\
Shopping at the gift shop & 168 & 44.4 \\
Bird watching & 162 & 42.9 \\
Visiting the visitor center & 132 & 34.9 \\
Eating at the snack bar & 131 & 34.7 \\
Hiking & 116 & 30.7 \\
Picnicking & 79 & 20.9 \\
Eating at the restaurant & 71 & 18.8 \\
Backpacking & 29 & 23.8 \\
Bouldering & 28 & 7.4 \\
Camping & 27 & 0.8 \\
Naturalist-led activities & 3 & 22.1 \\
\hline
\end{tabular}

Table 9 
Activity Participation by User Type

\begin{tabular}{|c|c|c|c|c|c|c|c|}
\hline \multirow[b]{2}{*}{ Activity } & \multicolumn{2}{|c|}{ Wilderness } & \multicolumn{2}{|c|}{ Long Valley } & \multirow[b]{2}{*}{ Chi-Sq } & \multirow[b]{2}{*}{ df } & \multirow[b]{2}{*}{ P-Value } \\
\hline & $\mathrm{f}$ & $\%$ & $\underline{f}$ & $\%$ & & & \\
\hline Backpacking & 29 & 23.8 & 0 & 0 & & & \\
\hline Camping & 27 & 22.1 & 0 & 0 & & & \\
\hline Picnicking & 38 & 31.1 & 41 & 16.0 & 11.444 & 1 & .001 \\
\hline Eating at the snack bar & 35 & 28.7 & 96 & 37.5 & 2.833 & 1 & .092 \\
\hline Eating at the restaurant & 10 & 8.2 & 61 & 23.8 & 15.086 & 2 & .001 \\
\hline Shopping at the gift shop & 28 & 23.0 & 140 & 54.7 & 33.704 & 1 & .000 \\
\hline Visiting the visitor center & 21 & 17.2 & 111 & 43.4 & 24.854 & 1 & .000 \\
\hline Bouldering & 15 & 12.3 & 13 & 5.1 & 6.274 & 1 & .012 \\
\hline Wildlife viewing & 37 & 30.3 & 132 & 51.6 & 15.071 & 1 & .000 \\
\hline Bird watching & 35 & 28.7 & 127 & 49.6 & 14.767 & 1 & .000 \\
\hline Photography & 72 & 59.0 & 207 & 80.9 & 20.393 & 1 & .000 \\
\hline
\end{tabular}

Note. Italicized p-values indicate significant differences

Table 10

Activity Participation by Residency 


\begin{tabular}{lrrrrrrrrr}
\hline \multirow{2}{*}{ Activity } & \multicolumn{2}{c}{ California } & \multicolumn{2}{l}{ US } & \multicolumn{2}{c}{ Intl } & & \\
Hiking & 105 & 94.6 & 7 & $100 / 0$ & 4 & 100.0 & & & \\
Backpacking & 27 & 34.3 & 1 & 14.3 & 1 & 25 & & & \\
Camping & 25 & 22.5 & 1 & 14.3 & 1 & 25 & & & \\
Picnicking & 68 & 25.0 & 7 & 11.1 & 4 & 9.3 & & & \\
Eating at the snack bar & 92 & 33.8 & 25 & 39.7 & 14 & 32.6 & .870 & 2 & .647 \\
Eating at the restaurant & 49 & 18.0 & 17 & 27.0 & 5 & 11.6 & 4.701 & 4 & .319 \\
Shopping at the gift shop 110 & 40.4 & 42 & 66.7 & 16 & 37.2 & 15.277 & 2 & .000 \\
Visiting the visitor center & 88 & 32.4 & 32 & 50.8 & 12 & 27.9 & 8.704 & 2 & .013 \\
Bouldering & 25 & 9.2 & 3 & 4.8 & 0 & 0.0 & & & \\
Wildlife viewing & 110 & 40.4 & 37 & 58.7 & 22 & 51.2 & 7.739 & 2 & .021 \\
Bird watching & 107 & 39.3 & 35 & 55.6 & 20 & 46.5 & 5.758 & 2 & .056 \\
Photography & 185 & 68.0 & 54 & 85.7 & 40 & 93.0 & 17.555 & 2 & .000 \\
\hline
\end{tabular}

Note. Italicized p-values indicate significant differences

\section{Visitor Attitudes and Preferences}

Subjects' attitudes and preferences towards crowding, displacement in the park, park safety, and management policies were also of interest. Subjects agreed with the statements that conditions in the park are safe and that there are adequate ranger patrols (Table 11). Wilderness subjects agreed with statements that there are plenty of campsites available, and that it is easy to make a reservation for a campsite. Subjects disagreed with statements that there are too many people at Mountain Station, that they have 
avoided parts of the park because of too many people, and that they have stayed away from the park during parts of the day because there are too many people.

Significant differences between Wilderness visitors and Long Valley visitors were present using a Mann-Whitney $U$ test for non-parametric statistics for adequate ranger patrols, too many people at Mountain Station, and would prefer to see fewer people. The Wilderness visitors mean rank score for ranger patrols was higher than the mean rank score for the Long Valley visitors, they had a higher mean rank score for too many people at Mountain Station, and they would prefer to see fewer people in the park.

When Wilderness survey subjects were asked if they thought the current capacity of 400 wilderness camping permits issued daily for the wilderness is an appropriate limit, $71.3 \%$ agreed, $22.1 \%$ did not know, and $0.8 \%$ disagreed.

A Mann-Whitney U test was conducted to look for significant attitude and preferences differences between male and female subjects (Table 12). A single significant difference was present, male subjects more strongly agreed (mean rank score 132.71) that there are adequate ranger patrols in the park than female subjects (mean rank score 110.72).

A Kruskal-Wallis test for non-parametric statistics was conducted to look for significant differences in attitudes and preferences by California, United States, and international residency (Table 13). No significant differences were present.

Table 11

Visitor Attitudes and Preferences 


\begin{tabular}{|c|c|c|c|c|c|}
\hline \multirow[b]{2}{*}{ Attitudes and Preferences } & Overall & \multicolumn{2}{|c|}{ Mean Rank Score } & \multirow[b]{2}{*}{ SD } & \multirow[b]{2}{*}{ P-Value } \\
\hline & n Score & Wilderness & Long Valley & & \\
\hline Adequate ranger patrols & 3.70 & 136.75 & 118.12 & .914 & .022 \\
\hline Conditions in park are safe & 4.23 & 194.00 & 186.61 & .489 & .421 \\
\hline Too many people Mountain Station & 2.19 & 196.09 & 172.24 & .764 & .007 \\
\hline $\begin{array}{l}\text { Avoided parts of park because } \\
\text { too many people }\end{array}$ & 1.88 & 184.04 & 177.29 & .482 & .404 \\
\hline Prefer to see fewer people in park & 2.55 & 206.39 & 177.92 & 1.058 & .007 \\
\hline $\begin{array}{l}\text { Stayed away from park during parts } \\
\text { of the day because too many people }\end{array}$ & 2.04 & 178.44 & 171.80 & .679 & .412 \\
\hline Plenty of campsites available & 3.43 & 23.50 & & 1.003 & \\
\hline Easy to make campsite reservation & 3.36 & 18.5 & & 1.046 & \\
\hline
\end{tabular}

Note. Scale 1-strongly disagree to 4-strongly agree; italicized Mann-Whitney U test p-values indicate significant differences

Table 12

Visitor Attitudes and Preferences by Gender 


\begin{tabular}{|c|c|c|c|c|}
\hline & Overall & \multicolumn{2}{|c|}{ Mean Rank Score } & \\
\hline Attitudes and Preferences & Mean Score & Male & Female & P-Value \\
\hline Adequate ranger patrols & 3.70 & 132.71 & 110.72 & .010 \\
\hline Conditions in park are safe & 4.23 & 185.34 & 195.41 & .260 \\
\hline Too many people Mountain Station & 2.19 & 178.64 & 181.03 & .776 \\
\hline $\begin{array}{l}\text { Avoided parts of park because } \\
\text { too many people }\end{array}$ & 1.88 & 184.00 & 171.69 & .118 \\
\hline Prefer to see fewer people in park & 2.55 & 189.62 & 182.43 & .480 \\
\hline $\begin{array}{l}\text { Stayed away from park during parts of } \\
\text { day because too many people }\end{array}$ & 2.04 & 172.18 & 177.12 & .532 \\
\hline Plenty of campsites available & 3.43 & 21.76 & 29.75 & .065 \\
\hline Easy to make reservation for campsite & 3.36 & 19.16 & 16.19 & .453 \\
\hline
\end{tabular}

Note. Italicized Mann-Whitney U test p-values indicate significant differences

Table 13

Visitor Attitudes and Preferences by Residency 


\begin{tabular}{|c|c|c|c|c|c|}
\hline \multirow[b]{2}{*}{ Attitudes and Preferences } & \multirow{2}{*}{$\begin{array}{c}\text { Overall } \\
\text { Mean Score }\end{array}$} & \multicolumn{3}{|c|}{ Mean Rank Scores } & \multirow[b]{2}{*}{ P-Value } \\
\hline & & $\mathrm{CA}$ & US & Intl & \\
\hline Adequate ranger patrols & 3.70 & 125.98 & 124.29 & 123.67 & .978 \\
\hline Conditions in park are safe & 4.23 & 188.77 & 196.45 & 179.51 & .589 \\
\hline Too many people Mountain Station & 2.19 & 183.01 & 172.95 & 167.23 & .357 \\
\hline $\begin{array}{l}\text { Avoided parts of park because } \\
\text { too many people }\end{array}$ & 1.88 & 179.81 & 178.85 & 178.39 & .991 \\
\hline Prefer to see fewer people in park & 2.55 & 190.50 & 172.25 & 186.82 & .388 \\
\hline $\begin{array}{l}\text { Stayed away from park during parts of } \\
\text { day because too many people }\end{array}$ & 2.04 & 175.94 & 178.63 & 153.01 & .167 \\
\hline
\end{tabular}

Note. Italicized Kruskal-Wallis test p-values indicate significant differences

Spearman's Rank Correlation Coefficient tests were conducted to look for relationships between attitudes and preferences and continuous visit and visitor attributes (Table 14). Number of nights spent in the wilderness and group size did not significantly correlate with attitudes and preferences. Number of miles hiked in the wilderness had weak negative correlations with agreement to statements there are adequate ranger patrols in the park, there are too many people at Mountain Station, and subjects would prefer to see fewer people in the park. Number of total previous park visits had a moderate negative correlation with the statement there are plenty of campsites available, and also had weak positive correlations with the statements there are too many people at Mountain Station, subjects would prefer to see fewer people in the park, and subjects have stayed away from the park during parts of the day because of too many people. Number of previous 2008 park visits had moderate negative correlations with the statements there are plenty of campsites available and it is easy to make a campsite reservation, and had a 
weak positive correlations with the statement subjects would prefer to see fewer people in the park. Hours spent in the wilderness had moderate positive correlations with statements there are plenty of campsites available and it is easy to make a campsite reservation, as well as weak negative correlations with statements there are adequate ranger patrols in the park and there are too many people at Mountain Station.

Table 14

Attitudes and Preferences by Visit/Visitor Attributes

\begin{tabular}{|c|c|c|c|c|c|c|}
\hline \multirow[b]{2}{*}{ Attitudes and Preferences } & \multicolumn{6}{|c|}{ Visit/Visitor Attributes } \\
\hline & Nights & Miles & Visits & '08 Visits & Size & Hours \\
\hline Adequate ranger patrols & -.162 & -.165 & .041 & .039 & .058 & -.170 \\
\hline Conditions in park are safe & .247 & -.035 & .037 & .040 & .076 & -.009 \\
\hline Too many people Mountain Station & -.013 & -.151 & .117 & .093 & -.025 & -.116 \\
\hline $\begin{array}{l}\text { Avoided parts of park because } \\
\text { too many people }\end{array}$ & -.036 & -.045 & .009 & .038 & -.092 & -.009 \\
\hline Prefer to see fewer people in park & -.050 & -.136 & .112 & .127 & -.031 & -.081 \\
\hline $\begin{array}{l}\text { Stayed away from park during part o } \\
\text { day because too many people }\end{array}$ & .114 & -.051 & .135 & .101 & -.087 & -.056 \\
\hline Plenty of campsites available & -.178 & .097 & -.367 & -.435 & -.015 & .533 \\
\hline Easy to make reservation for campsi & & & -.305 & -.350 & .039 & .588 \\
\hline
\end{tabular}

Note. Italicized correlation coefficients indicate significant relationships 
Three groups of questions addressed visitor perceptions of social and environmental impacts. On a 9-point crowding scale (1= not at all crowded, $3=$ somewhat crowded, $6=$ moderately crowded, $9=$ extremely crowded) the mean score was 2.88 . The mean rank scores were 225.09 and 172.54 for Wilderness visitors and Long Valley visitors respectively. These scores were significantly different, with a p-value of .0001 (Mann-Whitney U test). Mann-Whitney U test analysis indicated no significant difference ( $p$-value=.153) in perceptions of crowding between males (195.38) and females (179.16). A Kruskal-Wallis analysis of mean rank scores for CA residents (198.87), United State residents (161.86), and international residents (170.74), revealed that California residents significantly perceive the park to be more crowded, with a pvalue of .021 .

Perceptions of 16 potential environmental and social impacts in the park were also measured. Subjects did not perceive any of these issues to be a problem with overall mean scores ranging from 1.01 to 1.24 (Table 15). However, a Mann-Whitney U test detected that Wilderness subjects were significantly more likely to consider encountering large groups on a trail (mean rank score 190.15) and restrooms needing cleaning (mean rank score 150.26) to be problems than Long Valley subjects (mean rank scores 175.09 and 137.63 respectively). Mann-Whitney $U$ test analysis did not reveal significant perception differences between males and females (Table 16).

Table 15

Visitor Perceptions 


\begin{tabular}{|c|c|c|c|c|c|}
\hline Perception & $\begin{array}{l}\text { Overall } \\
\text { an Score }\end{array}$ & $\mathrm{SD}$ & $\begin{array}{r}\text { Mean } \\
\text { Wildernes } \\
\end{array}$ & $\begin{array}{l}\text { nk Score } \\
\text { ong Vall }\end{array}$ & Jalue \\
\hline Litter trail, campsite, picnic area & 1.17 & .431 & 186.32 & 190.28 & .597 \\
\hline Behavior of others & 1.13 & .454 & 185.81 & 186.83 & .864 \\
\hline Noise of others & 1.24 & .586 & 184.52 & 190.41 & .460 \\
\hline $\begin{array}{l}\text { Too long wait to take photo of } \\
\text { peak at Mountain Station }\end{array}$ & 1.05 & .537 & 125.82 & 124.77 & .615 \\
\hline Too many people Desert View & 1.05 & .278 & 117.00 & 121.94 & .163 \\
\hline Encounter large groups on trail & 1.11 & .398 & 190.15 & 175.09 & .006 \\
\hline Encounter groups $>15$ in wilderness & 1.06 & .269 & 54.00 & & \\
\hline Restrooms need cleaning & 1.17 & .537 & 150.26 & 137.63 & .023 \\
\hline Too close to other campers & 1.90 & 6.913 & 31.00 & & \\
\hline Too many people Wellman's Divide & 1.03 & .162 & 38.0 & & \\
\hline Too many people at San Jacinto Peal & k 1.28 & .678 & 32.5 & & \\
\hline People washing dishes stream/faucet & 1.01 & .116 & 37.5 & & \\
\hline Evidence illegal campfires & 1.03 & .159 & 39.5 & & \\
\hline Human waste along trail/campsite & 1.13 & .420 & 34.5 & & \\
\hline Finding a route to top of peak & 1.03 & .184 & 44.00 & & \\
\hline Seeing other visitors smoking & 1.01 & .096 & 161.17 & 160.93 & .897 \\
\hline
\end{tabular}

Note. Scale 1-not a problem to 4-big problem; italicized Mann-Whitney U test p-values indicate significant differences

Table 16

Visitor Perceptions by Gender 


\begin{tabular}{lccccc} 
& Overall & \multicolumn{4}{c}{ Mean Rank Score } \\
Perception & Mean Score & SD & Male & Female & P-Value \\
Litter trail, campsite, picnic area & 1.17 & .431 & 188.43 & 190.00 & .830 \\
Behavior of others & 1.13 & .454 & 188.71 & 182.67 & .302 \\
Noise of others & 1.24 & .586 & 188.18 & 189.07 & .909 \\
Too long wait to take photo of & & & & & \\
peak at Mountain Station & 1.05 & .537 & 125.08 & 124.86 & .904 \\
Too many people Desert View & 1.05 & .278 & 122.45 & 118.43 & .165 \\
Encounter large groups on trail & 1.11 & .398 & 182.54 & 175.47 & .189 \\
Encounter groups >15 in wilderness & 1.06 & .269 & 54.40 & 53.11 & .586 \\
Restrooms need cleaning & 1.17 & .537 & 139.44 & 146.08 & .220 \\
Too close to other campers & 1.90 & .129 & 30.67 & 30.00 & .564 \\
Too many people Wellman's Divide & 1.03 & .162 & 38.47 & 37.00 & .329 \\
Too many people at San Jacinto Peak & 1.28 & .678 & 33.43 & 29.47 & .272 \\
People washing dishes stream/faucet & 1.01 & .116 & 37.65 & 37.00 & .585 \\
Evidence illegal campfires & 1.03 & .159 & 39.80 & 38.50 & .436 \\
Human waste along trail/campsite & 1.13 & .420 & 43.16 & 46.64 & .082 \\
Finding a route to top of peak & 1.03 & .184 & 34.18 & 35.63 & .633 \\
Seeing other visitors smoking & 1.01 & .096 & 161.85 & 159.50 & .191 \\
\hline
\end{tabular}

Note. Scale 1-not a problem to 4-big problem; italicized Mann-Whitney U test p-values indicate significant differences

Kruskal-Wallis test was conducted to look for differences in perception of park conditions noticed by residency. At the .05 significance level, California residents were significantly more likely to notice large groups on trails; while, United States residents 
were significantly more likely to perceive litter at a trail, campsite, or picnic area (Table 17).

The subjects checked all that applied for 11 conditions that they noticed in the park relating to environmental impacts (Table 18). Subjects indicated that they noticed side trails, worn trails, trail erosion, downed trees, tree root exposure, tree damage, and vegetation loss on trails. Few subjects noticed the other impacts. Using chi-square analysis at the .05 significance level, Wilderness subjects were significantly more likely than Long Valley subjects to notice erosion along trails and tree root exposure along trails. Pearson's chi-square tests revealed no significant differences in conditions noticed by residency or gender.

Spearman's Rank Correlation Coefficient tests were conducted to determine relationships between perceptions and continuous visit and visitor attributes. Strong correlations were not present; however, numerous weak correlations were found (Table 19). Number of miles hiked in the wilderness had a weak negative correlation with encountering large groups on trails and a weak positive correlation with perceiving too many people at San Jacinto Peak. Income level had a weak positive correlation with seeing other visitors smoking. Group size had a moderate positive correlation with perceiving too many people at San Jacinto Peak. Hours spent in the wilderness had weak positive correlations with perceiving the noise of other visitors, too many people at San Jacinto Peak, and noticing human waste along a trail or campsite. Number of nights spent in the wilderness did not significantly correlate with any visitor perceptions. Additionally, perceptions of crowding were positively correlated with total previous 
visits $\left(\mathrm{r}_{\mathrm{s}}=.165\right)$ and previous visits in $2008\left(\mathrm{r}_{\mathrm{s}}=.157\right)$; and negatively correlated with number of miles hiked $\left(\mathrm{r}_{\mathrm{s}}=-.198\right)$, and hours spent in the wilderness $\left(\mathrm{r}_{\mathrm{s}}=-.107\right)$.

Table 17

Visitor Perceptions by Residency

\begin{tabular}{lccccccc}
\hline & Overall & \multicolumn{5}{c}{ Mean Rank Score } \\
Perception & Mean Score & SD & CA & US & Intl & P-Value \\
\hline Litter trail, campsite, picnic area & 1.17 & .431 & 190.76 & 198.28 & 164.31 & .030 \\
& & & & & & \\
Behavior of others & 1.13 & .454 & 188.59 & 183.58 & 177.60 & .428 \\
Noise of others & 1.24 & .586 & 187.83 & 190.55 & 189.72 & .958 \\
$\begin{array}{l}\text { Too long wait to take photo of } \\
\text { peak at Mountain Station }\end{array}$ & 1.05 & .537 & 125.71 & 123.50 & 123.50 & .489 \\
Too many people at Desert View & 1.05 & .278 & 121.45 & 119.66 & 120.62 & .880 \\
Encounter large groups on trail & 1.11 & .398 & 185.00 & 165.50 & 169.88 & .008 \\
& 1.17 & .537 & 141.84 & 140.47 & 145.93 & .868 \\
Restrooms need cleaning & & & & & & & \\
Seeing other visitors smoking & 1.01 & .096 & 160.91 & 159.50 & 163.84 & .409 \\
\hline
\end{tabular}

Note. Italicized Kruskal-Wallis test p-values indicate significant differences

Table 18

Environmental Conditions Noticed 


\begin{tabular}{|c|c|c|c|c|c|}
\hline \multirow[b]{2}{*}{ Condition } & \multicolumn{2}{|c|}{ Wilderness } & \multicolumn{2}{|c|}{ Long Valley } & \multirow[b]{2}{*}{ P-Value } \\
\hline & $\mathrm{f}$ & $\%$ & $\mathrm{f}$ & $\%$ & \\
\hline Worn trails & 41 & 33.6 & 84 & 32.8 & .781 \\
\hline Side trails & 67 & 54.9 & 148 & 57.8 & .595 \\
\hline Campsite vegetation loss & 1 & 0.8 & & & \\
\hline Vegetation loss on trails & 10 & 8.2 & 23 & 9.0 & .800 \\
\hline Vegetation loss at a picnic area & 0 & 0.0 & 1 & 0.4 & \\
\hline Campsite erosion & 4 & 3.3 & & & \\
\hline Erosion along trails & 39 & 32.0 & 43 & 16.8 & .001 \\
\hline Downed trees along trails & 29 & 23.8 & 46 & 18.0 & .186 \\
\hline $\begin{array}{l}\text { People in marked fragile areas } \\
\text { at the Nature Loop trail }\end{array}$ & 5 & 4.1 & 15 & 5.9 & .328 \\
\hline People breaking branches & 3 & 2.5 & 6 & 2.3 & \\
\hline Tree damage caused by humans & 7 & 5.7 & 30 & 11.7 & .067 \\
\hline Campsite root exposure & 0 & 0.0 & 0 & 0.0 & \\
\hline Tree root exposure on trails & 28 & 23.0 & 15 & 5.9 & .000 \\
\hline $\begin{array}{l}\text { Cigarette butts littered on trails } \\
\text { or around park }\end{array}$ & 9 & 7.4 & 12 & 4.7 & .290 \\
\hline
\end{tabular}

Note. Italicized p-values indicate significant differences

Table 19

Perceptions by Visit/Visitor Attributes 


\begin{tabular}{lccccc} 
& \multicolumn{5}{c}{ Visit/Visitor Attribute } \\
Perception & Nights & Miles & Income & Size & Hours \\
\hline Litter trail, campsite, picnic area & .038 & .051 & -.107 & .002 & .064 \\
Behavior of others & .138 & .036 & -.012 & -.094 & .055 \\
Noise of others & .005 & .055 & .007 & -.083 & .106 \\
Too long wait to take photo of & & -.028 & -.104 & .009 & -.052 \\
peak at Mountain Station & & & & & \\
Too many people Desert View & & .089 & -1.06 & .006 & .081 \\
Encounter large groups on trail & -.091 & -.116 & -.033 & .001 & -.050 \\
Encounter groups >15 in wilderness & .079 & .158 & -.204 & .017 & .176 \\
Restrooms need cleaning & -.159 & -.109 & .026 & .093 & .004 \\
Too close to other campers & .337 & .219 & & -.062 & .124 \\
Too many people Wellman's Divide & -.287 & .146 & -.152 & .079 & .127 \\
Too many people at San Jacinto Peak & .060 & .296 & -.099 & .359 & .281 \\
People washing dishes stream/faucet & & .184 & -.145 & -.040 & .048 \\
Evidence illegal campfires & & .143 & -.145 & .079 & .065 \\
Human waste along trail/campsite & -.089 & .126 & -.146 & .126 & .227 \\
Finding a route to top of peak & .087 & .027 & .067 & .152 & .058 \\
Seeing other visitors smoking & & -.004 & .157 & -.034 & -.025 \\
\hline
\end{tabular}

Note. Italicized correlation coefficients indicate significant relationships

\section{Summary}

This chapter has presented results from two visitor use surveys in Mount San Jacinto State Park. These results provide insight into Mount San Jacinto State Park visit and visitor attributes, visitor attitudes and preferences, and visitor perceptions. A discussion of these findings, theoretical and managerial implications, and future research occurs in the concluding chapter. 


\section{CHAPTER 5}

\section{DISCUSSION}

The purpose of this study was to assess Mount San Jacinto State Park visit and visitor attributes, visitor attitudes and preferences, and visitor perceptions of social and environmental impacts. Results of this study reflect subjects who are highly satisfied with their experiences and who do not perceive any significant issues related to social and environmental impacts at Mount San Jacinto State Park. Overall, the visitors perceive the park to be well managed; ratings of attitudes, preferences, and perceptions are extremely positive for nearly all conditions and issues measured.

\section{Summary}

The results of the study provide insight regarding Mount San Jacinto State Park visitors to both Long Valley and the Wilderness area. This section will address the seven research questions pertaining to Mount San Jacinto State Park visit and visitor attributes, visitor attitudes and preferences, and visitor perceptions.

Research question one: What are Mount San Jacinto State Park visit attributes? Visit attributes are somewhat specific to Mount San Jacinto State Park, as the park contains some unique features. The average group size is between 3 and 4 individuals and the majority of subjects intend to hike trails within the park rather than San Jacinto Peak. Nearly all subjects access the park by way of the Palm Springs Aerial Tramway. Subjects appear to mainly be first time visitors to the park, with the average person having previously visited the park a median of one time total and once in 2008. The 
subjects primarily participate in hiking, photography, wildlife viewing, shopping at the gift shop, bird watching, visiting the visitor center, and eating at the snack bar.

Wilderness subjects spend on average more than four hours in the wilderness area and about three-quarters are day-use visitors. Nearly all Wilderness subjects have acquired a day-use or overnight permit. Most Wilderness subjects hike the Round Valley Loop Trail and the majority of overnight visitors camp at Round Valley. These subjects hike nearly nine miles during their trip to the Wilderness.

Research question two: What are Mount San Jacinto State Park visitors' attributes? The attributes of Mount San Jacinto State Park visitors are similar to the characteristics of many wilderness visitors throughout California (Chavez, 2001). The visitors are mostly married, white or Latino, about 46 years old, highly educated, and most are from California. The majority of visitors from California are from the neighboring counties of Riverside, Los Angeles, San Diego, Orange, and San Bernardino. However, the park also receives a significant number of visitors from other states $(16 \%)$ and countries (11\%). Mount San Jacinto State Park visitors differ from other wilderness visitors as they have considerably high levels of income.

Research question three: What are Mount San Jacinto State Park visitors' attitudes and preferences towards crowding, displacement in the park, park safety, and management policies? The attitudes and preferences expressed by the subjects indicate a very satisfied clientele. The subjects strongly agree that there are adequate ranger patrols and that conditions in the park are safe. The subjects disagree with statements indicating there are too many people at Mountain Station, that they avoid parts of the park because of too many people, and that they stay away from the park during parts of the day 
because of too many people. There is less disagreement with the statement that they would prefer to see fewer people in the park (score midway between disagree and agree). The overnight Wilderness visitors agree that there are plenty of campsites available, that it is easy to make a reservation for a campsite, and that the current capacity of 400 Wilderness camping permits issued daily for the Wilderness is an appropriate limit.

Research question four: What are Mount San Jacinto State Park visitors' perceptions of social and environmental impacts? When asked about their perceptions of social conditions within the park, subjects overwhelmingly express that they perceive few issues to be present in the park. All 16 potential issues relating to the behavior of other visitors such as group encounters, illegal behavior, litter, and noise are perceived as not being a problem. Similarly, the visitors notice few environmental impacts in the park. Conditions that are noticed relate to the condition of trails including side trails, worn trails, erosion along trails, downed trees on trails, and tree root exposure on trails.

Research question five: Does Mount San Jacinto State Park visitor activity participation differ by user type or by residency? Activity participation is affected by both user type and residency. Wilderness subjects are more likely to picnic, while Long Valley subjects are more likely to eat at the restaurant, shop at the gift shop, visit the visitor center, view wildlife, watch birds, and participate in photography. California residents are more likely to picnic. Visitors from states other than California are more likely to shop at the gift shop, visit the visitor center, view wildlife, and watch birds. International residents are more likely to participate in photography.

Research question six: Do Mount San Jacinto State Park visitors' attitudes and preferences differ by user type, gender, residency, number of nights spent in the 
wilderness, number of miles hiked in the wilderness, number of total previous park visits, number of previous 2008 park visits, group size, or by number of hours spent in the wilderness? Visitors' attitudes and preferences are affected by visitor attributes. To a limited extent Wilderness visitors more strongly agree that there are adequate park ranger patrols, that there are too many people at Mountain Station, and that they would prefer to see fewer people in the park. There is only one difference in visitor attitudes and preferences related to gender, as male subjects more strongly agree that there are adequate ranger patrols in the park. Residency does not affect visitor attitudes and preferences.

Visit attributes also affect visitor attitudes and preferences. The more miles hiked in the wilderness, the less a subject agrees with statements that there are adequate park ranger patrols, that there are too many people at Mountain Station, and that they would prefer to see fewer people in the park. The greater number of total previous park visits, the more a subject agrees that there are too many people at Mountain Station, that they would prefer to see fewer people, and that they have avoided the park at certain times of day due to crowding; and, the less a subject agrees that there are plenty of campsites available. The greater the number of previous 2008 park visits, the more a subject agrees that they would prefer to see fewer people, and the less that subject agrees that it is easy to make a reservation for a campsite and that there are plenty of campsites available. The more hours spent in the wilderness, the more a subject agrees that it is easy to make a reservation for a campsite and that there are plenty of campsites available, and the less that subject agrees that there are adequate park ranger patrols and that there are too many 
people at Mountain Station. Attitudes and preferences do not differ by number of nights spent in the wilderness or group size.

Research question seven: Do Mount San Jacinto State Park visitors' perceptions of social and environmental impacts differ by user type, gender, residency, number of nights spent in the wilderness, number of miles hiked in the wilderness, income levels, group size, or by hours spent in the wilderness? Visitor perceptions differ by visitor attributes. Wilderness visitors perceive crowding and maintenance problems more than Long Valley visitors. In addition, they notice large groups, erosion along trails, and tree root exposure on trails more than Long Valley visitors. California residents are more likely to notice large groups on trails, while U.S. residents are more likely to perceive litter on a trail, at a campsite, or picnic area. Additionally, visitors in higher income ranges are more likely to notice others smoking.

Perceptions also differ by visit attributes. Perception of crowding is positively correlated with number of total previous visits and number of previous visits in 2008 . Number of miles hiked in the wilderness and number of hours spent in the wilderness is negatively correlated with perceptions of crowding. As subjects hike further in the wilderness, they are more likely to perceive that there too many people at Mount San Jacinto Peak, and they are less likely to notice large groups on trails. As visitor group size increases, subjects are more likely to perceive that there are too many people at San Jacinto Peak. The more hours a subject spends in the wilderness, the likelihood of the subject perceiving noise of other visitors, that there are too many people at San Jacinto Peak, and human waste along a trail or at a campsite increases. Visitor perceptions of 
environmental and social impacts are not related to number of nights spent in the wilderness.

\section{Discussion}

As park visitors are mostly married, white or Latino, about 46 years old, highly educated, and mostly from California, Mount San Jacinto State Park visitors are similar to other wilderness visitors throughout the state (Chavez, 2001). Their relatively high levels of income are much greater than the $\$ 20,000$ to $\$ 60,000$ reported by California wilderness visitors (2001) but some of this difference may be attributed to changes in income since 2001. The more recent California Outdoor Recreation Plan 2008 indicates that average levels of income of other California outdoor recreation users range from $\$ 50,000$ to $\$ 75,000$ (California State Parks, 2009).

Similar to previous outdoor research (Ho, Sasidharan, \& Elmendorf, 2005; Manning, 1999), wilderness visitor attitudes and preferences, as well as their perceptions, are not greatly affected by gender in Mount San Jacinto State Park. Women are less likely to agree with statements that there are adequate ranger patrols in the park. This difference found in this study is also consistent with previous research that suggests women may feel more threatened in the outdoors and therefore desire the presence of park personnel (Virden \& Walker, 1999). However, none of the subjects, including women, perceive conditions to be unsafe in the park. In this case, women may prefer the presence of park rangers as an assurance of continued safety.

Results of this study support the categorization of visitors into four visitor segments (valley day users, day use hikers, peak users, and overnight campground users). Visitor use levels, as well as temporal and spatial distribution, are uneven, with the 
greatest use occurring in Long Valley, on the Round Valley Loop, and on the San Jacinto Peak trail. Such uneven visitor use distribution is also reflected in previous outdoor recreation research (Manning, 1999). Subjects in these areas are more likely to perceive some levels of crowding. As visitors explore other areas of the park, they are less likely to agree that there are adequate ranger patrols.

Overall crowding in the park is rated slightly higher than "somewhat crowded" by Wilderness visitors and slightly lower than "somewhat crowded" by Long Valley visitors. These results differ from previous research that suggests visitors' perceptions of crowding are greater at more accessible locations (Manning, 1999). As Long Valley is a day trip destination for families and other groups, Long Valley visitors' expectations of solitude may be considerably less than Wilderness visitors. Cole (2001) found that day users are more tolerant of crowded conditions than overnight users. Additionally, Wilderness visitors may be affected by camping capacity permit limits, whereas Long Valley visitors are not turned away. As another measure of capacity, Wilderness and Long Valley visitors generally "disagree" with the statement that they would prefer to see few fewer people in the park. Clearly, from the perspective of Mount San Jacinto visitors crowding and social impacts are not an issue in the park.

\section{Managerial Implications}

Overall, visitors are very satisfied with their experiences at the park and park management, and they perceive few problems. Visitors do notice some trail conditions that might require attention, which may highlight the need to consider additional trail maintenance and management when budget and staffing allocations are determined. Previous research measuring perceptions of visitors and managers has found that visitors 
often do not perceive environmental conditions the same as park managers. Managers usually perceive impacts to be more severe (Manning, 1999). Moreover, additional educational programs that emphasize reducing impacts to resources may be successful at the park. Visitors who are spending more time and hiking more miles in the Wilderness are less likely to find ranger patrols adequate in the park. This may indicate a need for more patrol in the Wilderness area.

The results do not indicate visitor perceptions or preferences that would suggest concerns over social impacts or a need to change the capacity limits currently set for the Wilderness. More than $99 \%$ of the Wilderness visitors agree that the current capacity of 400 wilderness camping permits is an appropriate limit. Specific measures relating to capacity and crowding including the number of people at the Desert View Overlook, Wellman's Divide, and San Jacinto Peak are all rated as "not a problem." Similarly, the wait to take a photo of the peak from Mountain Station is not considered a problem, and encounters with large groups on a trail and in the Wilderness are not perceived as problems. Since park visitors are currently satisfied, management does not need to make any immediate changes to affect current crowding levels and capacity limits; however, consideration to maintaining current levels of satisfaction should be consider in the formation of long-term planning.

Management should consider setting impact indicators and standards of quality for these indicators, while visitors are pleased with park conditions and management policies in order to maintain visitor satisfaction. Visitor perceptions can be critical in setting social and environmental impact indicators, as well as setting standards of quality for these indicators (Newsome, Moore, \& Dowling, 2002). Additionally, this 
understanding of visitors' attitudes, preferences, and perceptions can assist in establishing maintenance and policy priorities during budget and resource allocations (Dorwart, Yeung, \& Moore, 2004).

\section{Theoretical Implications}

This research was undertaken to measure and examine Mount San Jacinto State Park visitors and their experiences in the park. As with much of the current outdoor research, significant relationships, differences, and correlations were revealed between visit and visitor attributes, visitor attitudes and preferences, and visitor perceptions. These findings suggest that future wilderness visitor research should continue to examine relationships between visit and visitor attributes, visitor attitudes and preferences, and visitor perceptions.

A model of how visitors' attitudes, preferences, and perceptions of environmental conditions can affect the outcome of their outdoor experiences is called the landscape perception interaction process model. In this model Zube, Sell, \& Taylor (1982) illustrate that social factors, such as perceptions, attitudes, or preferences, can affect visitor experiences. A significant percentage of the subjects in this study noticed numerous environmental impacts on trail conditions within the park, most frequently noting side trails, worn trails, and trail erosion. Dorwart (2007) states that visitors' experiences are negatively affected when they perceive undesirable park conditions such as poor trail maintenance.

However, subject satisfaction does not appear to have decreased as a result of the perception of these impacts in this study. To explain similar phenomenon in other outdoor recreation research, Manning (1999) refers to the cognitive dissonance theory 
when hypothesizing that as "recreation activities are voluntarily selected and sometimes involve a substantial investment of time, money, and effort, some people may rationalize their experience and report high levels of satisfaction, regardless of conditions" (p. 97). Mount San Jacinto visitors voluntarily visit the park, pay to ride the Palm Springs Aerial Tramway to Mountain Station, and possibly wait in hour-long lines to ride the tram. They may employ similar coping behaviors and rationalization to overcome the negative environmental conditions that they notice within the park.

\section{Study Limitations}

The limited financial resources for this research study restricted the days of data collection and necessitated that data collection occur over four weekends during July, August, and September of 2008. Although random probability sampling procedures common to wilderness survey research have been followed, this sampling procedure excluded opportunities to contact midweek visitors or visitors during other seasons. These visitors may be more sensitive to crowding and social impacts and may have changed their visitation patterns based on previous experiences in the park. The nature of in-person interviews prohibits the collection of data from nonusers. Cole (2001) emphasizes the importance of considering this population's needs and desires when setting management policy and during wilderness studies.

Recreational displacement occurs when recreationists dissatisfied with setting attributes, environmental impacts, or social conditions go to another location or visit at a different time (Robertson \& Regula, 1994). Such displacement may explain high levels of visitor satisfaction despite changing or undesirable recreational conditions (Shelby, 
Bregenzer, \& Johnson, 1988). Two questions in this survey address subjects' previous displacement. Eight point six percent of subjects report staying away from the park during parts of the day because of too many people, while $4.4 \%$ of subjects report avoiding parts of the park because of too many people. It would be interesting to look at the attitudes, preferences, and perceptions of visitors who report some level of displacement. With subjects reporting displacement and coping behaviors, it is likely that other visitors and nonusers also experience displacement. Analysis of midweek visitors, other season visitors, and nonusers' attitudes and preferences, as well as their perceptions of Mount San Jacinto State Park may provide important displacement and coping information.

Secondly, the limited time allocated for the project and the goal to contact as many visitors as possible during the four weekends resulted in visitor contacts at two locations, both in proximity to the Palm Springs Aerial Tramway. Visit and visitor attribute findings, particularly for Wilderness visitors, may have changed if data collection had occurred at locations well within the trail system such as at the Round Valley Campground.

Numerous statistical analysis tests could not be conducted due to small subsample sizes of international Wilderness visitors, U.S. resident Wilderness visitors, and bouldering participants. As these groups' attitudes and perceptions were not analyzed, future analysis of their experiences may provide varying levels of satisfaction with managerial policy and park conditions, as well as activity participations and use distribution patterns. 
A final limitation relates to the nature of the data. Although the visitors express extremely positive views of their experiences at Mount San Jacinto State Park, this pattern resulted in responses to most items that are heavily skewed. The positively skewed responses result in violations of a normal distribution of the data. Thus, the data have been analyzed using non-parametric statistics.

\section{Future Research}

Future research should attempt to collect data at additional locations within the park, during other seasons, and over a longer period of time. Research should be conducted to understand displaced and non-users' constraints, as well as their preferences for park management. Park managers should consider adopting a long-term research and management planning framework that utilizes indicators and standards for various social and environmental impacts to assist in decision-making and policy formation. For example, standards for the number of people encountered at specific park locations and the acceptable levels of change of specific campground and trail conditions could be developed. Additionally, data should be collected from a larger sample of wilderness users. Such research can be conducted to look for differences between overnight wilderness users and day use wilderness users. Cole (2001) indicates that such research is critical to setting management policy.

To help management understand differences between Long Valley and Wilderness visitors, future research should focus on visitors' intentions and motivations for visiting the park. Determining visitors' primary purposes for visiting may provide insight into their expectations, preferences, and perceptions. During the course of this research, interviewers reported that many subjects were surprised by the parks existence, 
as their purpose was to ride the Palm Springs Aerial Tramway rather than visit Mount San Jacinto State Park. Visitor motivation research may reveal new categories of visitors: accidental visitors and primary purpose visitors. Primary purpose visitors would likely have much different needs than the accidental visitors, and awareness of these visitor types would allow management to better serve both.

Conducting further research into the experiences, expectations, and motivations of the park's international visitors may allow management to better meet the needs of this large percentage of visitors. While international visitors make up $11 \%$ of the subjects in this study, small cell sizes of international Wilderness visitors often required omission of this group from the data analysis. Research specifically focusing on this group would provide greater insight into their temporal and spatial distribution patterns, as well as attitudes, preferences, and perceptions.

Additional research that may be of interest to park managers, would consider visitor perceptions of the park based on how they obtain information about the park. Park managers were interested in knowing how visitors obtain information about the park. This study provides descriptive data; however, future data analysis could look for differences in visit attributes, attitudes, preferences, and perceptions based on how subjects obtained park information.

In summary, based on the results of this study, the visitors to Mount San Jacinto State Park are similar to wilderness visitors throughout California. They feel that they are being provided with opportunities resulting in quality recreation experiences. Current levels of use and set capacity levels do not appear to be detracting from these experiences 
and visitors' responses to the survey are highly supportive of park management practices, wilderness use policies, and conditions within the park. 


\section{REFERENCES}

Absher, J. \& Lee, R. (1981). Density as an incomplete cause of crowding in backcountry settings. Leisure Sciences, 4, 231-247.

Alessa, L.B., Bennett, S.M., \& Kliskey, A.D. (2003). Effects of knowledge, personal attribution and perception of ecosystem health on depreciative behaviors in the intertidal zone of Pacific Rim National Park and Reserve. Journal of Environmental Management, 68, 207-218.

Alldredge, R. (1973). Some capacity theory for parks and recreation areas. Trends, 10, $20-29$.

Allen, S.W. (1948). Conservation and priorities in wilderness areas. In Proceedings of the Society of American Foresters Meeting. (pp. 101-104). Boston, MA.

Badger, T.J. (1975). Rawah Wilderness crowding tolerances and some management techniques: An aspect of social carrying capacity. Unpublished master's thesis, Colorado State University, Fort Collins, CO.

Beardsley, W. (1967). Cost Implications of Camper and Campground Characteristics in Central Colorado. USDA Forest Service. (RM-86)

Behan, R.W. (1974). Police state wilderness: A comment on mandatory wilderness permits. Journal of Forestry, 72, 98-99.

Borrie, W.T. \& R.M. Birzell. (2001). Approaches to measuring quality of the wilderness experience. In W.A. Friemund \& D.N. Cole (Eds.), 2001. Visitor Use Density and Wilderness Experience, 2000. Ogden, UT: USDA, Forest Service, Rocky Mountain Research Station. 
Bratton, S.P., Hickler, M.G., \& Graver, J.H. (1977). Trail and campsite erosion survey for Great Smoky Mountains National Park. US Department of Interior, Uplands Field Research Laboratory. (Management Report 16).

Brown, P. \& Haas, G. (1980). Wilderness recreation experiences: The Rawah case. Journal of Leisure Research, 12, 229-241.

Bultena, G.L. \& M.J. Taves. (1961). Changing wilderness images and forestry policy. Journal of Forestry, 59, 167-171.

Bumgardner, W., Waring, M., Legg, M., \& Goetz, L. (1988). Key indicators of campsite selection at Corps of Engineers lakes. Journal of Park and Recreation Administration, 6(2), 62-78.

Burch, W. R., Jr. (1964). Two concepts for guiding recreation management decisions. Journal of Forestry, 62, 707-712.

Burch, W. R. (1966). Wilderness-The life cycle and forest recreational choice. Journal of Forestry, 64, 606-610.

Burch, W.R. \& Wenger, W.D. (1967). The Social Characteristics of Participants in Three Styles of Family Camping. USDA Forest Service, Pacific Northwest Forest and Range Experiment Station. (Research Paper PNW-48).

California State Parks (2009). California Outdoor Recreation Plan 2008. June 4, 2009, retrieved from http://www.parks.ca.gov/pages/795/files/corp\%20april\%202008.pdf.

California State Parks. (2007). Mount San Jacinto SP. November 28, 2007, retrieved from http://www.parks.ca.gov/?page_id=636. 
Cantu, R., Housser, S., Hoffman, R., \& Rohling, J. (2002). Interpretive and Environmental Education Concept Plan. USDA, Forest Service, Enterprise Team. Prescott, AZ.

Chavez, D.J. (1997). "Bunny hops or vegetable tunnels? Perceptions and Preferences of Mountain Bike Riders on the San Jacinto Ranger District.” Western Journal of Applied Forestry, 12(2), 44-48.

Chavez, D.J. (2001). Managing Outdoor Recreation in California: Visitor Contact Studies 1989-1998. USDA, Forest Service, Pacific Southwest Research Station. (General Technical Report PSW-GTR-180).

Clark, A., \& Leung, Y. (2007). Getting out, going green: Outdoor recreation is linked to pro-environmental attitudes and behaviors. Parks and Recreation, 42, 26-31.

Cole, D.N. (2001). Day Users in Wilderness: How Different are They? Ogden, UT: USDA, Forest Service, Rocky Mountain Research Station. (RMRS-RP-31)

Cole, D.N. (2001). Management dilemmas that will shape wilderness in the $21^{\text {st }}$ century. Journal of Forestry, 99, 4-8.

Cordell, K.H. \& G.A. James. (1972). Visitors' Preferences for Certain Physical Characteristics of Developed Campsites. USDA Forest Service, Southeast Forest Experimental Station. (Research Paper SE-100)

Cordell, H.K. \& Sykes, C. (1969). User Preferences for Developed-Site Camping. USDA Forest Service. (Research Note SE-122)

Dana, S.T. (1957). Research in Forest Recreation. USDA Forest Service.

Dorfman, P. (1979). Measurement and meaning of recreation satisfaction: A case study of camping. Environment and Behavior, 11, 483-510. 
Dorwart, C. (2007). Exploring Visitors' Perceptions of the Trail Environment and Their Effects on Experiences in the Great Smokey Mountains National Park. Unpublished dissertation, North Carolina State University, Raleigh, NC.

Dorwart, C., Leung Y., \& Moore, R. (2004). Managing visitors' perceptions. Parks and Recreation, 39, 24-31.

Drury, N.B. (1949). The dilemma of our parks. American Forests, 55, 6-11 \& 38-39.

Echelberger, H.E. \& Moeller, G.H. (1977). Use and Users of the Cranberry Backcountry in West Virginia: Insights for Eastern Backcountry Management. USDA, Forest Service, Northeastern Forest Experiment Station. (Research Paper NE-363).

Ewert, A. (1988). The identification and modification of situational fears associated with outdoor recreation. Journal of Leisure Research, 20, 106-117.

Farrell, T., Hall, T., \& White, D. (2001). Wilderness campers' perception and evaluation of campsite impacts. Journal of Leisure Research, 33, 299-250.

Fisher, A.C. \& Kruitlla, J.V. (1972). Determination of optimal capacity of resourcesbased recreation facilities. Natural Resources Journal, 12, 417-434.

Flood, J.P., \& McAvoy, L.H. (2000). The influence of wilderness restoration programs on visitor experience and visitor opinions of managers. In D.N., Cole, S.F. McCool, W.T. Borrie, \& J. O'Loughlin. (Eds.), Wilderness Science in a Time of Change Conference-Volume 5: Wilderness Ecosystems, Threats, and Management, 2000. (pp. 193-198). Ogden, UT: USDA Forest Service, Rocky Mountain Research Station. (RMRS-P-15-VOL-5)

Floyd, M., Jang, H., \& Noe, F. (1997). The relationship between environmental concern and acceptability of environmental impacts among visitors to two U.S. national park settings. Journal of Environmental Management, 51, 391-412. 
Freimund, W.A. \& Cole, D.N. (2001). Use density, visitor experience, and limiting recreational use in wilderness: Progress to date and research needs. In W.A. Friemund \& D.N. Cole (Eds.), 2001. Visitor Use Density and Wilderness Experience, 2000. Ogden, UT: USDA, Forest Service, Rocky Mountain Research Station.

Frissell, S.S. \& Duncan, D.P. (1965). Campsite preference and deterioration in the Quetico-Superior canoe country. Journal of Forestry, 65, 256-260.

Frissell, S.S. \& Stankey, G.H. (1972). Wilderness environmental quality: Search for social and ecological harmony. In: Proceedings, Society of Foresters annual meeting, 1972 October 1-5; Hot Springs, AR. Washington, DC: Society of American Foresters; 170-183.

Glaspell, B. \& Puttkammer, A. (2001). Linking wilderness research and managementvolume 2. In Wright \& Vita (Eds.), Defining, Managing, and Monitoring Wilderness Visitor Experiences: An Annotated Reading List. Fort Collins, CO: USDA Forest Service, Rocky Mountain Research Station. (RMRS-GTR-79-VOL 2)

Graefe, A. R., Absher, J. D., Ye, Y., \& Nyaupane, G. (2005). Shasta and Trinity Lakes Boating Carrying Capacity Study. Riverside: USDA Forest Service. (Wildland Recreation and Urban Cultures Research Work Unit RWU-4902 Technical Report)

Grieser, K., Dawson, C., \& Schuster, R. (2006). Visitor perceptions of crowding: An exploratory study in the Mohonk Preserve. In J.G. Peden \& R.M. Schuster (Eds). Proceedings of the 2005 Northeastern Recreation Research Symposium. 
Newtown Square, PA: U.S. Forest Service, Northeastern Research Station: 212220.

Hancock, H.H. (1973). Recreation preference: Its relation to user behavior. Journal of Forestry, 71, 366-337.

Heberlein, T., Trent, J., \& Baumgartner, R. (1982). The influence of hunter density on firearm deer hunters' satisfaction: A field experiments. Transactions of the $47^{\text {th }}$ North American Natural Resource and Wildlife Conference, 665-76.

Hendee, J.C., Catton, W.R., Jr., Marlow, L.D., \& Brockman, C.F. (1968). Wilderness Users in the Pacific Northwest: Their Characteristics, Values and Management Preferences. [Abstract] .USDA, Forest Service, Pacific Northwest Forest and Range Experiment Station. (Research Paper PNW-61). Abstract retrieved December 3, 2008 from ERIC.

Hendricks, W.W. \& Greenwood, J.B. (2007). 2007 ARI Proposal Mt. San Jacinto State Park Visitor Use Impact Study. Unpublished report supplied by authors.

Hendricks, W.W., Hamilton, L., \& Bohlken, S. (2007). Economic Impact of Oceano Dunes SVRA Visitors. San Luis Obispo, CA: California Polytechnic State University, Recreation, Parks, \& Tourism Administration Program.

Hendricks, W.W., Love, T., \& Hamilton, L. (2003). Economic Impact of Morro Bay State Park Visitors. San Luis Obispo, CA: California Polytechnic State University, Recreation, Parks, \& Tourism Administration Program.

Hillery, M., Nancarrow, B., Griffin, G., \& Syme, G. (2001). Tourist perception of environmental impact. Annals of Tourism Research, 28, 853-867. 
Ho, C., Sasidharan, V., \& Elmendorf, W. (2005). Gender and ethnic variations in urban park preferences, visitation, and perceived benefits. Journal of Leisure Research, 37, 281-306.

James, G. \& Cordell, H. (1970). Importance of Shading to Visitors Selecting a Campsite at Indian Boundary Campground in Tennessee. USDA Forest Service. (Research Note SE-130)

Jubenville, A. (1971). A test of difference between wilderness recreation party leaders and party members. Journal of Leisure Research, 3, 116-119.

Kelly, J. (1977). Leisure socialization: Replication and extension. Journal of Leisure Research, 9, 121-32.

Kennedy, J.J. \& Brown, P.J. (1976). Attitudes and behavior of fisherman in Utah's Uinta Primitive Area. Fisheries, 1, 15-17.

Klukas, R.W. \& Duncan, D.P. (1967). Vegetational preferences among Itasca park visitors. Journal of Forestry, 56, 19-21.

Knudson, D.M. \& Curry, E.B. (1981). Campers’ perceptions of site deterioration and crowding. Journal of Forestry, 79, 92-94.

Krantz, M. (2007). Real-life episode 'Lost': Planner criticized for failing to notice attendess missing after mountain tour. Meeting News, 30, 1-38.

Kuentzel, W.F. \& Heberlein, T.A. (2003). More visitors, less crowding: Change and stability of norms over time at the Apostle Islands. Journal of Leisure Research, 35, 349-355.

LaPage, W.F. (1963). Some sociological aspects of forest recreation. Journal of Forestry, 61, 32-36. 
Lee, R. (1972). The social definition of outdoor recreation places. In R. William, N.H. Cheek, , \& L.T. Burch (Ed.), Social behavior, natural resources, and the environment (pp. 68-84). New York: Harper and Row.

Lee, R. (1975). The Management of Human Components in the Yosemite National Park Ecosystem: Final Research Report. Berkeley: University of California.

Leopold, A. (1934). Conservation economics. Journal of Forestry, 32, 537-544.

Lime, D.W. (1970). Research for determining use capacities of the Boundary Waters Canoe Area. Naturalist, 21, 8-13.

Lime, D.W. (1971). Factors Influencing Campground Use in the Superior National Forest of Minnesota. USDA Forest Service. (Research Paper NC-60)

Lime, D.W. (1972). Large Groups in Boundary Waters Canoe Area-Their Numbers, Characteristics, and Impact. USDA, Forest Service, North Central Forest Experiment Station. (Research Note NC-142)

Lime, D.W. \& Buchman, G. (1974). Putting wilderness permit information to work. Journal of Forestry, 72, 622-626.

Lime, D. W. \& Stankey, G. H. (1971). Carrying capacity: Maintaining outdoor recreation qualities. In: Recreation Symposium Proceedings; 1971 October 12-14; Syracuse, NY. Upper Darby, PA: USDA, Forest Service, Northeastern Forest Experiment Station: 174-184.

Love, L. (1964). Summer Recreational Use of Selected National Forest Campgrounds in the Central Rocky Mountains. USDA Forest Service. (Research Paper RM-5)

Lucas, R.C. (1964a). Recreational Use of the Quetico-Superior Area. USFS Lakes States Forest Experimental Station. (Research Paper LS-8) 
Lucas, R.C. (1964b). Wilderness perception and use: The example of the Boundary Waters Canoe Area. Natural Resource Journal, 2, 394-411.

Lucas, R.C. (1970). User Evaluation of Campgrounds on Two Michigan National Forests. USDA Forest Service. (Research Paper NC-44)

Lucas, R.C. (1979). Perceptions of non-motorized recreational impacts: A review of research findings. In Recreational Impact on Wildlands. USDA Forest Service. (Research Paper INT-253)

Lucas, R.C. (1985). Visitor Characteristics, Attitudes, and Use Patterns in the Bob Marshall Wilderness Complex, 1970-82. USDA Forest Service. (Research Paper INT-345)

Lucas, R.C. (1987). Perspectives on the history of wilderness research. In R.C. Lucas (Comp.) Proceedings: National Wilderness Research Conference: Issues, Stateof-Knowledge, Future Directions. Ogden, UT: Intermountain Research Station. (General Technical Report INT-220).

Lucas, R.C. \& Priddle, G. (1964). Environmental perception: a comparison of two wilderness areas. Annals of the Association of American Geographers, 54, 42829.

Lynn, N. \& Brown, R. (2003). Effects of recreational use impacts on hiking experiences in natural areas. Landscape and Urban Planning, 64, 77-87.

Manfredo, M.J., Fishbein, M., Haas, G.E., \& Watson, A.E. (1990). Attitudes toward prescribed fire policies. Journal of Forestry, 88, 19-23. 
Manning, R.E. (2000). Coming of age: History and trends in outdoor recreation research. In: W.C. Gartner \& D.W. Lime (Eds.), Trends in Outdoor Recreation, Leisure and Tourism (pp. 121-130). New York: CABI Publishing.

Manning, R. E. (1999). Studies in outdoor recreation: Search and research for satisfaction (2nd ed.). Corvallis: Oregon State University Press.

Manning, R.E., Lime, D., Freimund, W., \& Pitt, D. (1996). Crowding norms: Alternative measurement approaches. Leisure Sciences, 21, 219-229.

McConnel, K. (1977). Congestion and willingness to pay: A study of beach use. Land Economics, 53, 185-95.

McEwen, D. (1986). Recreation quality and the market for tent camping. Journal of Park and Recreation Administration, 4(2), 83-95.

Merriam, L.C., Jr. (1963). A Land Use Study of the Bob Marshall Wilderness Area of Montana. Forest and Conservation Experiment Station. (Bulletin 26).

Merriam, L.C., Jr. (1970). Challenge of changing forest use. Journal of Forestry, 68, 289293.

Merriam, L.C. \& Ammons, R.B. (1968). Wilderness users and management in three Montana areas. Journal of Forestry, 66, 390-395.

Merriam, L.C. \& Smith, C.K. (1974). Visitor impact on newly developed campsites in the Boundary Waters Canoe Area. Journal of Forestry, 72, 627-630.

Morgan, J.T. (1970). User capacities of the Boundary Waters Canoe Area-The QueticoSuperior Found. In Institution on the Boundary Waters Canoe Area (pp. 82-84).

Moss, W.T., Shackelford, L., \& Stokes, G.L. (1969). Recreation and personality. Journal of Forestry, 67, 182-184. 
Murray, J.B. (1974). Appalachian Trail Users in the Southern National Forests: Their Characteristics, Attitudes, and Management Preferences. USDA Forest Service, Southeastern Forest Experiment Station. (Research Paper SE-116)

Newsome, D., Moore, S.A., \& Dowling, R.K. (2002). Natural area tourism: Ecology, impacts and management. Clevedon: Channel View Publications.

Nielsen, J.M. \& Shelby, B. (1977). River-running in the Grand Canyon: How much and what kind of use? In River recreation Management and research Symposium (pp. 160-177). St. Paul: USDA, Forest Service, North Central Forest Experiment Station. (General Technical report NC-28).

Noe, F., Hammitt, W., \& Bixler, R. (1997). Park user perceptions of resource and use impacts under varied situations in three national parks. Journal of Environmental Management, 49, 323-336.

Outdoor Recreation Resources Review Commission. (1962a). Outdoor Recreation for America: A Report to the President and to the Congress. Washington, DC: US Government Printing Office.

Outdoor Recreation Resources Review Commission (1962b). Wilderness and Recreation: A Report on Resources, Values, and Problems. Berkley, CA: Wildland Research Center, University of California. (Report 3).

Price, C. (1977). Public preference and the management of recreational congestion. Regional Studies, 13, 125-139.

Priddle, G.B. (1964). Recreational use and wilderness perception of the Algonquin Park Interior. Unpublished master's thesis, Clark University, Worcester, MA. 
Priskin, J. (2003). Tourist perceptions of degradation caused by coastal nature-based recreation. Environmental Management, 32, 189-204.

Robertson, R.A., \& Regula, J.A. (1994). Recreational displacement and overall satisfaction: A study of Central Iowa's licensed boaters. Journal of Leisure Research, 26(2), 174-181.

Roggenbuck, J.W. \& Lucas, R.C. (1987). Wilderness use and user characteristics: A state-of-knowledge review. In R.C. Lucas (Ed.), National Wilderness Research Conference: Issues, State of Knowledge, Future Directions, 1987. Fort Collins, CO: USDA, Forest Service, Intermountain Research Station.

Schreyer, R. \& Roggenbuck, J.W. (1978). The influence of experience expectations on crowding perceptions and social-psychological carrying capacities. Leisure Sciences, 1, 373-394.

Shafer, E.L. \& Burke, H.D. (1965). Preferences for outdoor recreation facilities in four state parks. Journal of Forestry, 63, 512-518.

Shafer, E.L. \& Thompson, R. (1968). Models that describe use of Adirondack campgrounds. Forest Science, 14, 383-91.

Shaw, S.M. (1986). Leisure, recreation or free time? Measuring time usage. Journal of Leisure Research, 18, 177-189.

Shelby, B. (1980). Crowding models for backcountry recreation. Land Economics, 56, 43-55.

Shelby, B. (1981). Encounter norms in backcountry settings-Studies of Three Rivers. Journal of Leisure Research, 13, 129-138. 
Shelby, B., Bregenzer, N., \& Johnson, R. (1988). Displacement and product shift: Empirical evidence from Oregon Rivers. Journal of Leisure Research, 20(3), 274288.

Shelby, B. \& Colvin, R. (1982). Encounter measures in carrying capacity research: Actual, reported, and diary contacts. Journal of Leisure Research, 14, 350-360.

Shelby, B., Danley, M.S., Gibbs, K.C., \& Petersen, M.E. (1982). Preferences of backpackers and river runners for allocation techniques. Journal of Forestry, 416419.

Shelby, B. \& Nielsen, J.M. (1976). River Contact Study Final Report, Part II and III. Mimeographed Report to the National Park Service, Grand Canyon National Park, Arizona.

Shelby, B., Vaske, J., \& Heberlein, T. (1989). Comparative analysis of crowding in multiple locations: Results from fifteen years of research. Leisure Sciences, 11, 269-291.

Sierra Club. (1949). Wilderness: A wasted heritage. A statement of wilderness policy. San Francisco: Sierra Club.

Stankey, G. (1973). Visitor Perception of Wilderness Recreation Carrying Capacity. USDA Forest Service. (Research Paper INT-142)

Stankey, G.H., Lucas, R.C., \& Lime, D.W. (1976). Crowding in parks and wilderness. Design and Experiment, 7, 38-41.

Stone, G.P. \& Taves, M.J. (1956). Research into the human element in wilderness use. In Society of American Foresters, 1956 (pp. 26-32). Washington DC: Society of American Foresters. 
Sumner, E.L. (1936). Special Report on a Wildlife Study in the High Sierra in Sequoia and Yosemite National Parks and Adjacent Territories. Washington, DC: U.S. National Park Service Records, National Archives.

Takahashi, L.Y. \& Milano, M.S. (2004). Visitors' characteristics, preferences and perception of the impacts of public use at Salto Morato Natural Reserve. In Proceedings From: Fourth Social Aspects and Recreation Research Symposium. San Francisco, California: San Francisco State University.

Tarrant, M.A. (1999). Variability of the perceived crowding scale: A research note. Leisure Sciences, 21, 159-164.

Taves, M.J., Hathaway, W., \& Bultena, G. (1960). Canoe Country Vacationers. St. Paul: University of Minnesota. (Miscellaneous Report 39).

The Trailmaster, Inc. (Artist). (2007). San Jacinto Peak Trail Map, [Online Image]. Retrieved May 26, 2009 from California State Parks. http://www.parks.ca.gov/default.asp?page_id=25257

Virden, R.J., \& Walker, G.J. (1999). Ethnic/racial gender variations among meanings given to, and preferences for, the natural environment. Leisure Sciences, 21, 219239.

Wagar, J. A. (1964). The carrying capacity of wild lands for recreation. [Forest Science Monograph 7.] Washington, DC: Society of American Foresters, 1-24.

Wagar, J.A. (1974). Recreational carrying capacity reconsidered. Journal of Forestry, 7, 274-278.

Wagar, J.V. (1946). Services and facilities for forest recreationists. Journal of Forestry, $44,883-887$. 
Watson, A. E., Cole, D. N., Turner, D. L., \& Reynolds, P. S. (2000). Wilderness Recreation Use Estimation: A Handbook of Methods and Systems. Ogden, UT: USDA Forest Service, Rocky Mountain Research Station. (RMRS-GTR-56)

Watson, A.E., Cordell, H.K., \& Hartmann, L.A. (1989). Characteristics of wilderness users in outdoor recreation assessments. In L. Marty \& P.J. Brown (Eds.), Recreation and Park Management: Papers From the First National Symposium of Social Science in Resource Management, 1986 (pp. 1-10). Corvallis, OR: Oregon State University, College of Forestry.

Watson, A.E., Niccolucci, M.J., \& Williams, D.R. (1993). Hikers and Recreational Stock Users: Predicting and Managing Recreation Conflicts in Three Wildernesses. Ogden, UT: USDA Forest Service, Intermountain Research Station. (Research Paper INT-468)

Watson, A.E., Williams, D.R., Roggenbuck, J.W., \& Daigle, J.J. (1992). Visitor Characteristics and Preferences for Three National Forests Wildernesses in the South. (Research Paper INT-455)

White, D., Hall, T., \& Farrell, T. (2001). Influence of ecological impacts and other campsite characteristics on wilderness visitors' campsite choices. Journal of Park and Recreation Administration, 19(2), 83-97.

Zinser, C. (1995). Outdoor Recreation. New York: John Wiley and Sons.

Zube, E.H., Pitt, D.G., \& Anderson, T.W. (1974). Perception and measurement of scenic resources in the southern Connecticut River Valley. (Pub. R-73-1, 191 p.) Amherst, MA: Institute for Man and His Environment, University of Massachusetts. 
Appendix A: Long Valley Visitor Survey 


\section{Mount San Jacinto State Park \\ Long Valley Visitor Survey}

Hello my name is ... I am working for Cal Poly as a research assistant on behalf of Mt. San Jacinto State Park. Would you please consider participating in a park visitor survey so California State Parks can provide you with a quality outdoor recreation experience? Your participation will take approximately 5 minutes. The study is completely voluntary and your responses will remain anonymous. As only one person can be interviewed from your party, I would like to interview the person who is 18 or older and whose birthday is closest to today.

1. Are you staying in Long Valley today or are you hiking into wilderness past the ranger's station? Which best describes your trip today?

_ Visiting Long Valley _ Hiking Desert Loop Trail and/or Nature Trail

2. Did you enter the park by taking the Palm Springs Aerial Tramway? _ Yes _ No

IF NO ASK, Where did you enter the park?

3. How many people are in your group today?

4. How many times have you been to this park?

5. How often have you visited this park in the last year?

6. I'm going to read a list of activities. Please tell me those that you have participated in during your visit today.

_ Picnicking

_ Eating at the Mountain

Station snack bar

Eating at the Mountain

Station restaurant

Shopping at the

Mountain Station gift shop
Visiting the Mountain Station

State Park Visitor Center/Store

_ Bouldering

_ Wildlife viewing

_ Bird watching

_ Photography

_ Naturalist-led activities

_ Other:

7. How crowded is Mount San Jacinto State Park? Please answer this question using a scale from 1-9. 1=Not At All Crowded 3=Somewhat Crowded 6=Moderately Crowded 9=Extremely Crowded (REPEAT SCALE AS NECESSARY, SO PARTICIPANTS GIVE A NUMBER) $\quad 123456789$

8. Please indicate whether or not you agree with the following statements, using a scale from 1-5. 1=Strongly Disagree 2=Disagree 3=Agree 4=Strongly Agree DK=Don't Know (REPEAT THE SCALE AS NECESSARY, SO THAT PARTICIPANTS GIVE YOU A NUMBER)

1234 DK There are adequate park ranger patrols in the park. 
1234 DK Conditions in the park are safe.

1234 DK There are too many people at Mountain Station.

1234 DK I have avoided parts of the park because there are too many people.

1234 DK I would prefer to see fewer people in the park.

1234 DK I have stayed away from the park during parts of the day because there are too many people.

9. During this visit to Mount San Jacinto State Park, how much of a problem did you find the following issues to be, using a scale from 1-4. 1= Not a Problem 2=Slight Problem 3=Moderate Problem 4= Big Problem NA=Not Applicable (REPEAT THE SCALE AS NECESSARY, SO THAT PARTICIPANTS GIVE YOU A NUMBER)

1234 NA Litter along a trail, at a campsite or at a picnic area

1234 NA The behavior of other visitors

1234 NA The noise of other visitors

1234 NA Too long of a wait to take a photo of the peak from Mountain Station

1234 NA Too many people at a Desert View overlook

1234 NA Encountering large groups of people (8+ people in a group) on a trail

1234 NA Restrooms that need cleaning

1234 NA Seeing other visitors smoking around Long Valley or on trails

10. Have you noticed any of the following conditions at park during this visit. (READ LIST TO PARTICIPANTS AND CHECK ALL THAT APPLY)

Worn trails

Side trails

_ Vegetation loss on trails

_ Vegetation loss at a picnic

area

Erosion along trails

_Downed trees along trails
People in marked fragile areas at the Nature Loop trail

_.People breaking branches off trees

Tree damage caused by humans

Tree root exposure on trails

_Cigarette butts littered on trails or around the park

These final questions are to help us get a picture of who visits the park. All of these questions are voluntary and you may decline to answer any of them.

11. Male or female? _ Female _ Male (don't need to ask, just check)

12. What is your marital status? _ Married _ Unmarried

13. What is your present age? years

14. What is the last year of school that you have completed? (do no read list, choose one number)
12345
678
9101112
13141516
171819202122
Elementary Middle
High School
College
Post Graduate 
15. What is your approximate annual household income? (don't read list, check one only)

Less than $\$ 40,000$
- $\$ 40,000$ to $\$ 60,000$
$-\$ 60,001$ to $\$ 80,000$
$-\$ 80,001$ to $\$ 100,000$
$-\$ 100,001$ to $\$ 120,000$
$-\$ 120,001$ to $\$ 140,000$

_ $\$ 140,001$ to $\$ 160,000$

$\$ 160,001$ to $\$ 180,000$

$\$ 180,001$ to $\$ 200,000$

— Greater than $\$ 200,000$

16. What racial category or categories best describes you? (don't read list, check one or more)

_ American Indian or

Alaskan Native Asian

_ Black or African

American

_ Cambodian

_ Central American

_ Chinese

- Chicano

_ Cuban

_ Filipino

_ Indian

_ Japanese
_ Korean

_ Malaysian

_ Mexican

_ Middle Eastern

_ Native Hawaiian or other

Pacific Islander

_ Pakistani

_ Puerto Rican

_ South American

_ Taiwanese

_ Vietnamese

— White

_ Other:

17. Do you live in California?

If yes ask, What county do you live in:

_ San Bernardino

_ Orange Yes No (PROCEED TO PAGE)

_ Los Angeles

_ Riverside

_ Other

18. Are you a resident of the US or an international visitor? _ US _ International If U.S. ask, what state do you live in?

If international ask, what country do you live in?

19. Ask of CA \& US only, What is your zip code? 
20. How did you obtain information about Mount San Jacinto State Park? (DO NOT READ LIST. CHECK ALL THAT APPLY)

_ State Parks Website

San Jacinto State Park

_ Palm Spring Aerial Tramway

Brochure

Friends or Family

_ Word of mouth

_ At a hotel

_ Travel agent

_ Travel/Hiking magazine

_ Book

_ Newspaper

_ Other:

THANK YOU FOR TAKING THE TIME TO PARTICIPATE IN THIS SURVEY. WE APPRECIATE YOUR CONCERN FOR AND INTEREST IN THE FUTURE OF MT. SAN JACINTO STATE PARK. 
APPENDIX B: Wilderness Visitor Survey 


\section{Mount San Jacinto State Park \\ Wilderness Survey}

Hello my name is ... I am working for Cal Poly as a research assistant on behalf of Mt. San Jacinto State Park. Would you please consider participating in a park visitor survey so California State Parks can provide you with a quality outdoor recreation experience? Your participation will take approximately 5 minutes. The study is completely voluntary and your responses will remain anonymous. As only one person can be interviewed from your party, I would like to interview the person who is 18 or older and whose birthday is closest to today.

1. Are you staying in Long Valley today or are you hiking into wilderness past the ranger's station? Which best describes your trip today?

_ Hiking to the San Jacinto Peak and back in one day

__ Hiking along trails within the park

_ Other (RECORD RESPONSE)

2. Did you enter the park by taking the Palm Springs Aerial Tramway? _ Yes _No IF NO ASK, Where did you enter the park?

3. How many people are in your group today?

4. How many times have you been to this park?

5. How often have you visited this park in the last year?

6. During this visit to the park, are you staying overnight in the park or are you a day use visitor?

_ Overnight visitor _ _ Day use visitor

\section{ASK OF DAY USE VISITORS ONLY}

7. How many hours do you plan to stay in the park beyond the tram building?

8. Do you have a permit today? _ Yes _ N0

\section{ASK OF OVERNIGHT VISITORS ONLY}

9. How many nights are you staying at a wilderness campsite(s) in the state park?

10. What wilderness campsite(s) will you be using while you are staying overnight in the state park? (check all that apply)

\footnotetext{
Round Valley

_ Tamarack Valley
} Little Round Valley

_ Strawberry Junction

_ Other 
11. Do you have a wilderness camping permit for this trip? _ Yes _ No

\section{ASK OF EVERYBODY}

12. Do you plan on hiking to San Jacinto Peak during your trip? _ Yes _ No

13. During this visit to San Jacinto State Park, what trails will you or have you hiked? (do not read list, check all that apply, may need to probe)

_ Round Valley Loop

_ Willow Creek Trail

_ Pacific Crest Trail

_ Trail to San Jacinto Peak

_ Marion Mountain Trail

_ Deer Springs Trail
_ Suicide Rock Trail

_ Skyline Ridge Cross-Country

_Route (AKA Cactus to

Clouds/Sunrise)

Other trails (ask for trail(s) name)

14. Approximately how many total miles will you hike while in the park during this visit?

15. I'm going to read a list of activities. Please tell me those that you have participated in during your visit today.

_ Hiking

_ Backpacking

_ Camping Picnicking

_ Eating at the Mountain

Station snack bar

_Eating at the Mountain

Station restaurant
_ Shopping at the Mountain

Station gift shop Visiting the Mountain Station State Park Visitor Center/Store

_ Bouldering

_ Wildlife viewing

_ Bird watching

_ Photography

_ Naturalist-led activities

_ Other:

16. How crowded is Mount San Jacinto State Park? Please answer this question using a scale from 1-9. 1=Not at all Crowded 3=Somewhat crowded 6=Moderately Crowded 9= Extremely Crowded. (REPEAT THIS SCALE AS NECESSARY, SO THAT PARTICIPANTS GIVE YOU A NUMBER) 123456789

17. Please indicate whether or not you agree with the following statements, using a scale from 1-5. 1=Strongly Disagree 2=Disagree 3=Agree 3=Strongly Agree DK=Don't Know (REPEAT THE SCALE AS NECESSARY, SO THAT PARTICIPANTS GIVE A NUMBER) 1234 DK There are adequate park ranger patrols at Mount San Jacinto State Park.

1234 DK Conditions in the park are safe.

1234 DK There are too many people at Mountain Station. 
1234 DK I have avoided parts of the park because there are too many people.

1234 DK I would prefer to see fewer people in the park.

1234 DK I have stayed away from the park during parts of the day because there are too many people.

1234 DK There are plenty of camping sites available.

1234 DK It is easy to make a reservation for a campsite.

18. During this visit to Mount San Jacinto State Park, how much of a problem did you find the following issues to be, using a scale from 1-4.

1= Not a Problem 2=Slight Problem 3=Moderate Problem 4= Big Problem N/A (REPEAT THE SCALE AS NECESSARY, SO THAT PARTICIPANTS GIVE A NUMBER)

1234 NA Litter along a trail, at a campsite, or at picnic area

1234 NA The behavior of other visitors/campers

1234 NA The noise of other visitors/campers

1234 NA Too long of a wait to take a photo of the peak from Mountain Station

1234 NA Too many people at a Desert View overlook

1234 NA Encountering large groups of people (8+ people in a group) on a trail

1234 NA Encountering groups larger than the 15 person limit in the wilderness

1234 NA Restrooms that need cleaning

1234 NA Being too close to other campers

1234 NA Too many people at Wellman's Divide

1234 NA Too many people at the top of San Jacinto Peak

1234 NA People washing dishes in a stream or at a faucet

1234 NA Evidence of illegal campfires

1234 NA Human waste along a trail or at campsite

1234 NA Finding a route to the top of the peak

1234 NA Seeing other visitors smoking around Long Valley or on trails

19. Please indicate if you have you noticed any of the following conditions at Mount San Jacinto State Park during this visit. (READ LIST TO PARTICIPANTS)

Worn trails

Side trails

_ Vegetation loss at

campsites

_ Vegetation loss on trails

_ Vegetation loss at a picnic

area

Erosion at campsites

Erosion along trails

Downed trees along trails
People in marked fragile areas at the Nature Loop trail

_.People breaking branches off trees

_ Tree damage caused by humans

- Tree root exposure at campsites

Tree root exposure on trails

Cigarette butts littered on trails or around the park

20. Do you think the current capacity of 400 wilderness camping permits issued daily for the wilderness is an appropriate limit? Yes No Don't Know

If no, ask.... How many permits do you think should be issued each day? 
These final questions are to help us get a picture of who visits the park. All of these questions are voluntary and you may decline to answer any of them.
21. Male or female? Female Male (don't need to ask, just check)

22. What is your marital status? _ Married _ Unmarried

23. What is your present age? years

24. What is the last year of school that you have completed? (do no read list, choose one number)
12345
678
9101112
13141516
171819202122
Elementary Middle
High School
College
Post Graduate

25. What is your approximate annual household income? (don't read list, check one only)

_Less than $\$ 40,000$

$\$ 40,000$ to $\$ 60,000$

— $\$ 60,001$ to $\$ 80,000$

— $\$ 80,001$ to $\$ 100,000$

— $\$ 140,001$ to $\$ 160,000$

— $\$ 160,001$ to $\$ 180,000$

— $\$ 100,001$ to $\$ 120,000$

_ $\$ 180,001$ to $\$ 200,000$

— $\$ 120,001$ to $\$ 140,000$

_ Greater than $\$ 200,000$

26. What racial category or categories best describes you? (don't read list, check one or more)

American Indian or
Alaskan Native
— Asian
_ Black or African
American
- Cambodian
- Central American
- Chinese
_ Chicano
_ Cuban
_ Filipino
_ Indian
_ Japanese

27. Do you live in California?

If yes ask, What county do you live in:

— San Bernardino

_ Orange

_ Korean

_ Malaysian

- Mexican

_ Middle Eastern

_ Native Hawaiian or other

Pacific Islander

_ Pakistani

_ Puerto Rican

_ South American

_ Taiwanese

_ Vietnamese

- White

Other

_ Los Angeles Yes No (PROCEED TO PAGE)

28. Are you a resident of the US or an international visitor? _ US _ International 
If U.S. ask, what state do you live in?

If international ask, what country do you live in?

29. Ask of CA \& US only, What is your zip code?

30. How did you obtain information about Mount San Jacinto State Park? (DO NOT READ LIST. CHECK ALL THAT APPLY)

_ State Parks Website

_ San Jacinto State Park

Brochure

Friends or Family

Word of mouth

At a hotel

_ Palm Spring Aerial

Tramway
_ Travel agent

_ Travel/Hiking magazine

Book

- Newspaper

_ Other:

THANK YOU FOR TAKING THE TIME TO PARTICIPATE IN THIS SURVEY. WE APPRECIATE YOUR CONCERN FOR AND INTEREST IN THE FUTURE OF MT. SAN JACINTO STATE PARK 
APPENDIX C: Informed Consent Form 


\section{INFORMED CONSENT TO PARTICIPATE IN A SURVEY OF MOUNT SAN JACINTO STATE PARK VISITORS}

Katherine Wassenberg a graduate student in the Recreation, Parks, and Tourism Administration Management Specialization, M.S in Agriculture at San Luis Obispo is conducting a Mount San Jacinto State Park visitor use survey for her thesis. The purpose of the study is to collect information about visitors' experiences and perceived impacts at Mount San Jacinto State Park.

You are being asked to take part in this study by completing an oral questionnaire. Please respond to the best of your ability and as accurately as possible. Your participation will take approximately 5-6 minutes. Please be aware that you are not required to participate in this research and you may discontinue your participation at any time without penalty. You may also omit any items on the questionnaire you prefer not to answer.

There are no risks associated with participating in this study. Your responses will be provided anonymously to protect your privacy. Potential benefits associated with the study include visitor perceptions and experiences as a component of the Long Valley management plan within the park.

If you have questions regarding this study or would like to be informed of the results when the study is completed, please feel free to contact Katherine Wassenberg at (805) 748-1002, or email at kwassenb@calpoly.edu. If you have questions or concerns regarding the manner in which the study is conducted, you may contact Susan Opava, Dean of Research and Graduate Programs, at 756-1508, sopava@ calpoly.edu.

If you agree to voluntarily participate in this research project as described, please indicate your agreement by completing the oral questionnaire. Thank you for your participation in this research. 